\title{
Nonlinear absolute sea-level patterns in the long-term-trend tide gauges of the West Coast of North America
}

https://doi.org/10.1515/nleng-2020-0024

Received Feb 26, 2019; accepted Nov 12, 2019.

\begin{abstract}
The research issue of which are the present relative and absolute rates of rise and accelerations for North America is here addressed. The data of the 20 long-termtrend (LTT) tide stations of the West Coast of North America with more than 80 years of recorded data are shown. The absolute rates of rise are computed by considering the absolute vertical velocity of Global Navigation Satellite System (GNSS) antennas near the tide gauges, and the relative rate of sea-level rise from the tide gauge signals. The 20 LTT stations along the West Coast of North America show an average relative rate of rise of $-0.38 \mathrm{~mm} / \mathrm{yr}$., an average acceleration of $+0.0012 \mathrm{~mm} / \mathrm{yr}^{2}$, and an average absolute rate of rise of $+0.73 \mathrm{~mm} / \mathrm{yr}$. This is the first paper publishing a comprehensive survey of the absolute sea-level rates of rise along the West Coast of North America using the reliable information of relative sea-level rates of rise from LTT tide gauges plus the absolute subsidence rates from different GNSS antennas close to the tide gauge installations.
\end{abstract}

Keywords: tide gauges; GPS; sea levels; subsidence

\section{Introduction}

Because sea levels oscillate with well-known periodicities in the 60-year range, like other climate parameters [1, 2], more than 60 years of continuous recording from the same tide gauge, without any major perturbation, are needed to compute a reliable slope by linear fitting, and more than 90 years are needed to compute a reliable acceleration by parabolic fitting. There are 20 Long Term Trend (LTT) tide stations along the West Coast of North America, from Alaska to Panama. These stations are Ketchikan,

\footnotetext{
*Corresponding Author: Alberto Boretti, Department of Mechanical Engineering, College of Engineering, Prince Mohammad Bin Fahd University, Al Khobar, Saudi Arabia, E-mail: a.a.boretti@gmail.com
}

AK, USA, Sitka, AK, USA, Juneau, AK, USA, Unalaska, AK, USA, Prince Rupert, Canada, Point Atkinson, Canada, Vancouver, Canada, Victoria, Canada, Tofino, Canada, Friday Harbor, WA, USA, Seattle, WA, USA, Neah Bay, WA, USA, Astoria, OR, USA, Crescent City, CA, USA, San Francisco, CA, USA, Santa Monica, CA, USA, Los Angeles, CA, USA, La Jolla, CA, USA, San Diego, CA, USA, Balboa, Panama. The measured monthly average mean sea levels (MSL) relative to the tide gauge instrument are given by the Permanent Service for Mean Sea Level (PSMSL) [3]. Analyses of these data are offered by different providers such as PSMSL, sealevel.info [4], National Oceanic and Atmospheric Administration (NOAA) [5], Système d'Observation du Niveau des Eaux Littorales (SONEL) [6].

The coupling of relative sea-level data from tide gauges and data of the absolute position of antennas from satellite permits to attribute the relative sea-level rise of a specific coastal site to the growth of the water volume or the sinking of the land [7].

The Global Positioning System (GPS) time series, from a constellation of satellites which is used for navigation and measurements of precise geodetic position of antennas, are given and analysed by different providers, such as SONEL, [6], Nevada Geodetic Lab (NGL) [8], or [9], and National Aeronautics and Space Administration (NASA) Jet Propulsion Laboratory (JPL) [10]. While the analysis of sea level data is straightforward, the analysis of GNSS data is more complicated hence there is a need to use multiple providers.

Discontinuities, outliers, seasonality, skewness, and heteroscedasticity are common problems in the estimation of velocities from the GNSS coordinate time series [9]. Additionally, subsidence patterns may also be genuinely non-linear also over the short time windows typically covered by the GNSS time series, as it is the case in areas subjected to abrupt crustal movements such as earthquakes [11].

Except in the very few cases where the GNSS antenna is co-located with the tide gauge, and precise leveling is ensured between the GNSS antenna and the tide gauge instrument, there is no guarantee that the absolute vertical velocity of an inland GNSS antenna is an accurate estima- 
tion of the absolute vertical velocity of the tide gauge instrument. This aspect has been addressed by [12].

The GNSS monitoring of antennas is a much better estimation than a global glacial isostatic adjustment (GIA) model computation. It is indeed quite popular to correct the relative sea-level rise trend by a GIA computation such as $[13,14]$. However, global GIA models account for only one of the many components of land motion, completely neglecting any possible crustal movement. The GIA correction has been seriously questioned by [15].

It is well accepted that the correction of the relative rate of rise of the sea level by the absolute velocity of a GNSS antenna nearby the tide gauge returns the absolute rate of rise of the sea levels with higher accuracy [16]. If the GNSS correction is more accurate than the correction by a global GIA model such as $[13,14]$ that does not include any regional subsidence or uplift, nevertheless technicalities limit the accuracy of the GNSS vertical velocities in a specific location, and nearby antennas may also exhibit a strongly variable pattern of subsidence. Hence, in the following sections, one relative MSL result will be coupled to multiple GNSS results, for every tide gauge location.

The difference between the GNSS computations by different providers is the different method of data analysis, the different realignments, and breakpoints, and (in the case of antennas still active) also the number of data points considered. NGL is usually more up-to-date in their analysis, which is based on a much larger number of antennas.

The total number of GNSS antennas considered by SONEL for the entire world is 493 (June 6, 2018). JPL has a few more stations. The total number of GNSS antennas considered by JPL for the entire world is 2822 (June 6, 2018). NGL has many more stations than JPL. The total number of GNSS antennas considered by NGL for the entire world is 15277 (June 6, 2018).

Although in principle the computation of the subsidence rate from a GNSS position time series should be straightforward, technicalities such as satellite drift, break-points alignments, resolution of discontinuities, make the evaluation of the subsidence rate subjected to a much larger uncertainty than what is shown by the different providers, that only compute the fitting accuracy.

While nearby GNSS antennas may, in some locations, suffer from dramatically different subsidence rates, the same GNSS antenna should have about the same subsidence rate from different providers. This is not the case.

While it is impossible to know the real accuracy of every estimation, it may only be judged the consistency in between the subsidence rates provided by the different providers SONEL, JPL and NGL as a measure of reliability. Additionally, more weight may be given to the GNSS antennas closer to, rather than farther from a tide gauge location.

As the NGL network is much more widespread and the data set is generally more complete, usually, the subsidence rate of the tide gauge for every location is taken as the NGL value of a co-located GNSS antenna, or, if no GNSS antenna is close enough, an average of the NGL values of nearby GNSS antennas.

While the chosen value for the subsidence rate at a tide gauge is still somehow arbitrary, this is the best opportunity presently available. Even if the inaccuracy is sometimes larger than the trend, the proposed absolute subsidence rate and absolute rates of rise of the sea levels are the best possible option available.

If GNSS data is lacking, the Glacial Isostatic Adjustment (GIA) vertical velocities VM2 from [13, 14] are used. This computation does not include the contribution of local subsidence, and other regional crustal movements, that may be large.

Even though climate models predict accelerated sea level rise, it is well established that long-term-trend tide gauge measurements show that there has been no detectable acceleration in the rate of sea level rise [17-45], just to name a few.

\section{Method}

Two regressions are usually applied to the measured relative sea levels of a tide gauge record to compute the relative sea-level rate of rise and acceleration.

The rate of rise of the sea level is historically computed as the first order coefficient of linear regression. A linear regression:

$$
y(x)=A+B \cdot x
$$

returns the sea level rate of rise $u$ as slope B.

The acceleration of the sea level is computed since more recently as twice the second-order coefficient of linear regression. A quadratic regression

$$
y(x)=A^{\prime}+B^{\prime} \cdot x+C \cdot x^{2}
$$

returns the acceleration $a$ taken as 2.C.

Figure 1 presents an example of the MSL of Brest. In Figure 1.a and $\mathrm{b}$ are the raw data with applied linear and parabolic fittings. In a the gaps (264 missing months) are filled, in $b$ the gaps are not filled. The $\mathrm{R}^{2}$ is also given as an estimation of the fitting accuracy. This is, unfortunately, only an estimation of the fitting uncertainties. The major issue in computing the rates of rise and accelerations of the sea level is the lack of good quality data, with often 


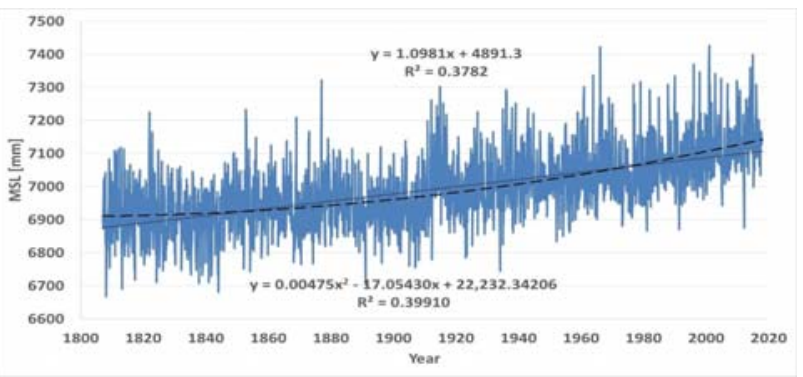

(a)

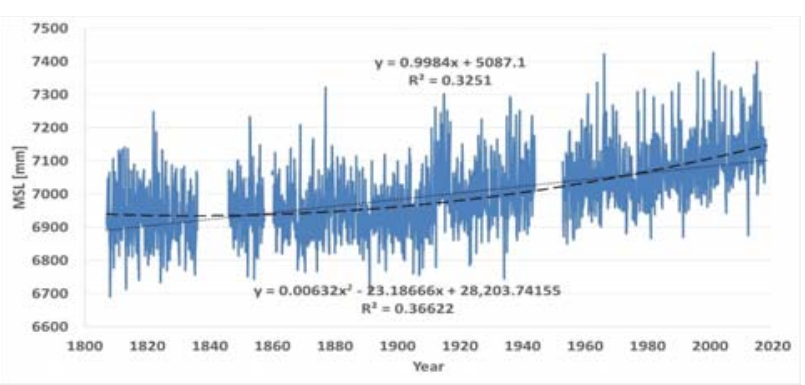

(b)

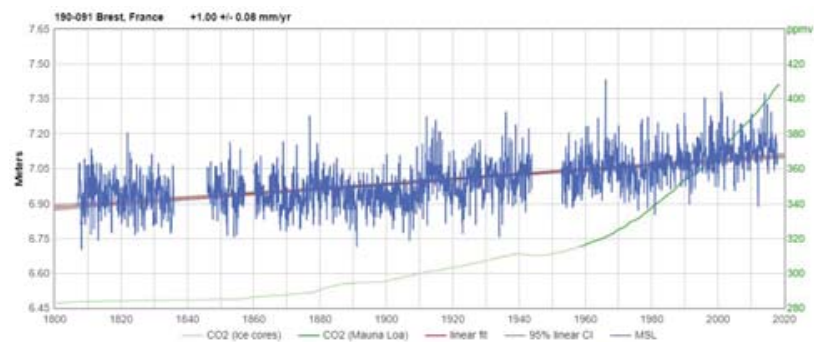

(c)

Figure 1: MSL of Brest, the oldest tide gauge in the PSMSL database

records that are too short, with gaps, and originating from different tide gauges of different land and sea contributions, sometimes also misaligned each other.

With gaps filled, the rate of rise and the acceleration are $1.0981 \mathrm{~mm} / \mathrm{yr}$. and $0.0095 \mathrm{~mm} / \mathrm{yr}^{2}$.

With the gaps, the rate of rise and the acceleration are $0.9984 \mathrm{~mm} / \mathrm{yr}$. and $0.01264 \mathrm{~mm} / \mathrm{yr}^{2}$.

Some providers of sea level analyses, such as [4], use slightly different approaches, where the raw data is first processed and cleared, and then two fittings having a common first-order coefficient are applied, and a different $x$ is used. Obviously, the computed rates of rise and accelerations do not practically change, as MS Office Excel provides the same rates of rise and accelerations of other statistical methods applied to the same data.

For the case of Brest, from [4], a linear regression in $\mathrm{x}$ $=($ date -1913.62$)$, i.e., $1913.62=1913 / 8$, returns

$\mathrm{y}=\mathrm{B}+\mathrm{M} \cdot \mathrm{x}$ $\mathrm{y}=6997.783+0.997 \cdot \mathrm{x} \mathrm{mm}$

while a quadratic regression in $\mathrm{x}$ returns

$\mathrm{y}=\mathrm{B}^{\prime}+\mathrm{M} \cdot \mathrm{x}+\mathrm{A} \cdot \mathrm{x}^{2}$

$\mathrm{y}=6973.966+0.997 \cdot \mathrm{x}+0.00635 \cdot \mathrm{x}^{2} \mathrm{~mm}$

[4] then prefers to use a $95 \%$ confidence interval rather than $\mathrm{R}^{2}$ as a measure of the still only statistical fitting accuracy. If the record does not satisfy quality and length requirements, the computation of the rate of rise and the acceleration is wrong whatever may be the confidence interval.

The slope is thus $0.997 \mathrm{~mm} / \mathrm{yr}$. vs. the $0.9984 \mathrm{~mm} / \mathrm{yr}$. of the simple linear fitting of the raw data with gaps, for a difference of $0.001 \mathrm{~mm} / \mathrm{yr}$., while the acceleration is thus $0.01269 \mathrm{~mm} / \mathrm{yr}^{2}$ vs. the $0.01264 \mathrm{~mm} \mathrm{yr}^{2}$ of the simple parabolic fitting of the raw data with gaps, for a difference of $+0.00005 \mathrm{~mm} / \mathrm{yr}^{2}$.

By taking as the present (2018) sea level rate of rise and acceleration $0.9984 \mathrm{~mm} / \mathrm{yr}$. and $0.01264 \mathrm{~mm} / \mathrm{yr}^{2}$, the constant acceleration sea level rise by 2100 is $124 \mathrm{~mm}$. By taking as the present (2018) sea level rate of rise and acceleration $0.997 \mathrm{~mm} / \mathrm{yr}$. and $0.01269 \mathrm{~mm} / \mathrm{yr}^{2}$, the constant acceleration sea level rise by 2100 is also $124 \mathrm{~mm}$. Considering the present debate is about the missing meter, or meters, of sea-level rise by 2100 , and no-quality short segmented records are given same relevance of high-quality records originated by a single tide gauge instrument that has recorded continuously in the same location over more than a century, these differences may be considered irrelevant.

For better details, if needed, of the data provided in the next sections, that originates from www.sealavel.info, the reader is referred to the web site, and to the work by [46].

The subsidence rate of the land is historically computed as the first order coefficient of linear regression. The linear regression is also applied to the absolute vertical position of the GNSS record for antennas located nearby tide gauge installations. The linear regression now returns the absolute velocity $w$ as the slope B. In this case, the major source of uncertainties are the many corrections of drifts and misalignments, additional to the short records. Better information is here given in the NGL web site.

The absolute rates of rise of the sea levels are then computed as $v=u+w[16]$.

\section{Results}

Here below are the analyses of the relative rates of rise and accelerations of the sea level in the 20 Long Term Trend (LTT) tide stations of the West Coast of North Amer- 
ica, Ketchikan, AK, USA, Sitka, AK, USA, Juneau, AK, USA, Unalaska, AK, USA, Prince Rupert, Canada, Point Atkinson, Canada, Vancouver, Canada, Victoria, Canada, Tofino, Canada, Friday Harbor, WA, USA, Seattle, WA, USA, Neah Bay, WA, USA, Astoria, OR, USA, Crescent City, CA, USA, San Francisco, CA, USA, Santa Monica, CA, USA, Los Angeles, CA, USA, La Jolla, CA, USA, San Diego, CA, USA, Balboa, Panama.

Figure 2 presents a map with the relative sea-level rise trends in the world locations with more than 80 years of data in the PSMSL database, with the West Coast of North America in evidence.

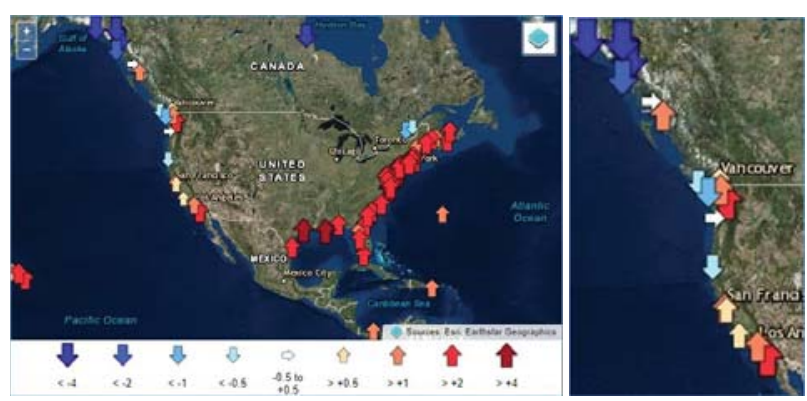

Figure 2: Locations of the tide gauges with more than 80 years of data in the PSMSL database. Image reproduced modified after [3]

\subsection{Ketchikan, AK, USA}

Ketchikan is the south eastern most city in Alaska. The MSL trend at Ketchikan, AK, USA, Figure 3, is $-0.33 \mathrm{~mm} / \mathrm{yr}$. with a $95 \%$ confidence interval of $\pm 0.22 \mathrm{~mm} / \mathrm{yr}$., based on MSL data from 1919/1 to 2017/12. The acceleration is $0.01808 \pm 0.01746 \mathrm{~mm} / \mathrm{yr}^{2}$.

The closest GNSS Stations from SONEL are AIS1, with absolute vertical velocity $0.88 \pm 0.33 \mathrm{~mm} / \mathrm{yr}$.,AIS5 with a signal not robust, AIS6, with no data. AIS6 has a distance-totide-gauge of 29,331 m, AIS1 has a distance-to-tide-gauge of 29,308 $\mathrm{m}$, and AIS5 has a distance-to-tide-gauge of 29,308 $\mathrm{m}$. Hence, all these GNSS antennas are relatively far from the tide gauge.

According to JPL, AIS1 has an absolute vertical velocity of $0.463 \pm 0.525 \mathrm{~mm} / \mathrm{yr}$., AIS2 has absolute vertical velocity $-0.538 \pm 1.399 \mathrm{~mm} / \mathrm{yr}$. According to NGL, AIS1 (data 1996.0520 to 2008.1068 ) has absolute vertical velocity $0.269 \pm 0.770 \mathrm{~mm} / \mathrm{yr}$., AIS2 (data 1996.3860 to 2008.0821 ) has absolute vertical velocity $-1.772 \pm 1.125 \mathrm{~mm} / \mathrm{yr}$., AIS5 (data 2008.0876 to 2018.4367) has absolute vertical velocity $0.819 \pm 0.936 \mathrm{~mm} / \mathrm{yr}$., AIS6 (data 2008.0876 to 2018.4367 ) has absolute vertical velocity $0.524 \pm 0.885 \mathrm{~mm} / \mathrm{yr}$.

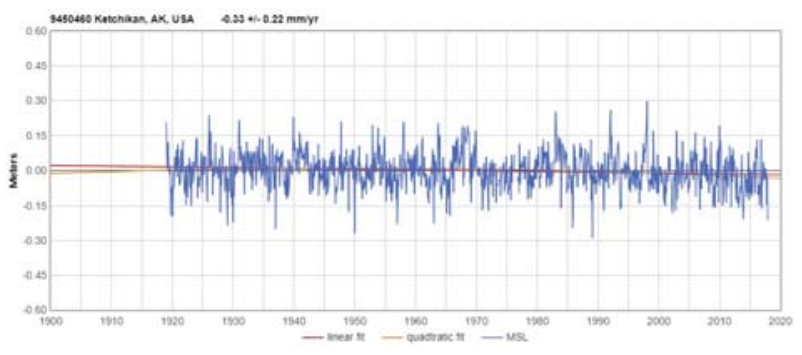

(a)

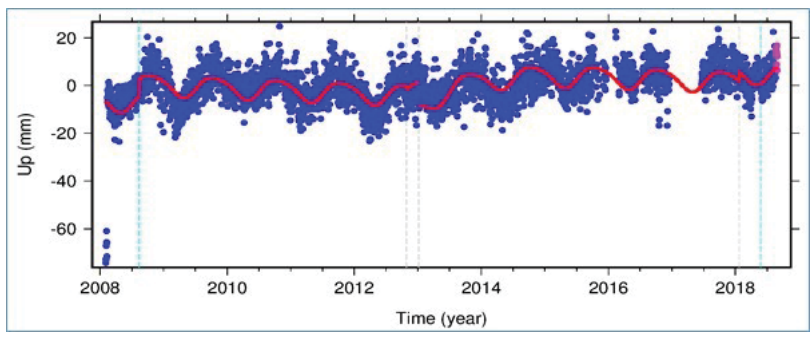

(b)

Figure 3: (a) MSL data for Ketchikan, AK, USA. Image reproduced modified after [4]. (b) GNSS time series for AIS6. Image reproduced modified after NGL.

From the NGL results, the likely absolute vertical velocity of the tide gauge instrument is taken as the average subsidence rate of the nearby GNSS antennas, -0.175 $\mathrm{mm} / \mathrm{yr}$.

The maximum and minimum subsidence rates are 0.819 and $-1.772 \mathrm{~mm} / \mathrm{yr}$. respectively.

\subsection{Sitka, AK, USA}

The MSL trend at Sitka, AK, USA, Figure 4, is $-2.33 \mathrm{~mm} / \mathrm{yr}$. with a $95 \%$ confidence interval of $\pm 0.27 \mathrm{~mm} / \mathrm{yr}$., based on MSL data from 1924/5 to 2017/12. The acceleration is $0.01631 \pm 0.02273 \mathrm{~mm} / \mathrm{yr}^{2}$.

The closest GNSS Stations from SONEL are BIS1, with absolute vertical velocity $1.80 \pm 0.51 \mathrm{~mm} / \mathrm{yr}$., BIS5 of signal not robust, BIS6, with no data. BIS6 has a distance-totide-gauge of $24,948 \mathrm{~m}$, BIS1 has distance-to-tide-gauge of 24,922 m, BIS5 has distance-to-tide-gauge of 24,922 m. Hence, also here the GNSS antennas are relatively far from the tide gauge. According to JPL, BIS1 has absolute vertical velocity $1.465 \pm 0.789 \mathrm{~mm} / \mathrm{yr}$.

According to NGL, BIS1 (data 2000.2218 to 2008.5941) has an absolute vertical velocity of $1.052 \pm 0.777 \mathrm{~mm} / \mathrm{yr}$., BIS2 (data 2010.7762 to 2014.2286) has an absolute vertical velocity of $0.394 \pm 1.644 \mathrm{~mm} / \mathrm{yr}$., BIS5 (data 2008.5175 to 2018.4367) has an absolute vertical velocity of $2.280 \pm 0.803$ 


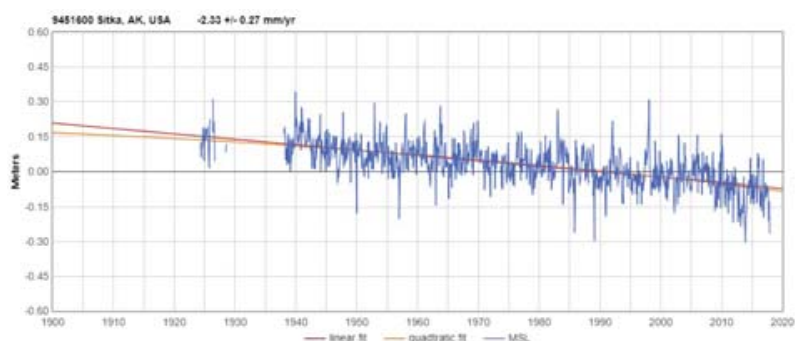

(a)

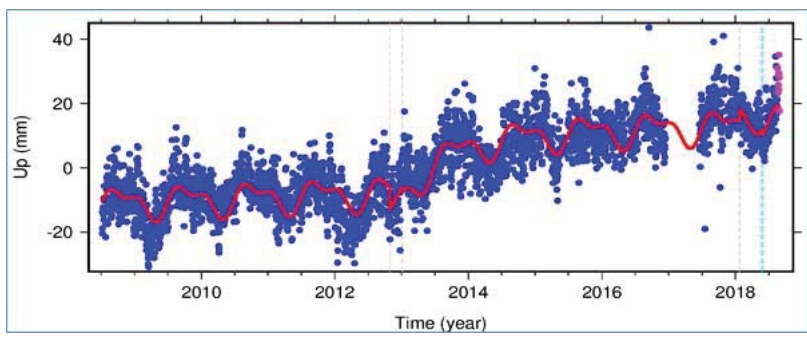

(b)

Figure 4: (a) MSL data for Sitka, AK, USA. Image reproduced modified after [4]. (b) GNSS time series for BIS6. Image reproduced modified after NGL.

mm/yr., BIS6 (data 2008.5175 to 2018.4367) has an absolute vertical velocity of $2.267 \pm 0.840 \mathrm{~mm} / \mathrm{yr}$.

From the NGL results a likely absolute vertical velocity of the tide gauge instrument is taken as the average subsidence rate of the nearby GNSS antennas, $+1.498 \mathrm{~mm} / \mathrm{yr}$. The maximum and minimum subsidence rates are 2.280 and $0.394 \mathrm{~mm} / \mathrm{yr}$. respectively.

\subsection{Juneau, AK, USA}

The MSL trend at Juneau, AK, USA, Figure 5, is -13.16 $\mathrm{mm} / \mathrm{yr}$. with a $95 \%$ confidence interval of $\pm 0.35 \mathrm{~mm} / \mathrm{yr}$., based on MSL data from 1936/1 to 2017/12. The acceleration is $-0.0378 \pm 0.0322 \mathrm{~mm} / \mathrm{yr}^{2}$.

The closest GNSS Stations from SONEL are JNU1, with no data, AB50, of absolute vertical velocity $16.68 \pm 1.49$ $\mathrm{mm} / \mathrm{yr}$. JNU1 has distance-to-tide-gauge of 12,348 m, AB50 has distance-to-tide-gauge of $15,291 \mathrm{~m}$.

According to JPL, AB50 has an absolute vertical velocity of $20.522 \pm 1.345 \mathrm{~mm} / \mathrm{yr}$.

According to NGL, AB50 (data 2005.6290 to 2018.4367) has an absolute vertical velocity of $17.745 \pm 0.974 \mathrm{~mm} / \mathrm{yr}$., JNU1 (data 2003.0719 to 2018.4367) has absolute vertical velocity $14.820 \pm 0.890 \mathrm{~mm} / \mathrm{yr}$.

From the NGL results, a likely absolute vertical velocity of the tide gauge instrument is taken as the average subsidence rate of the nearby GNSS antennas, $16.283 \mathrm{~mm} / \mathrm{yr}$.

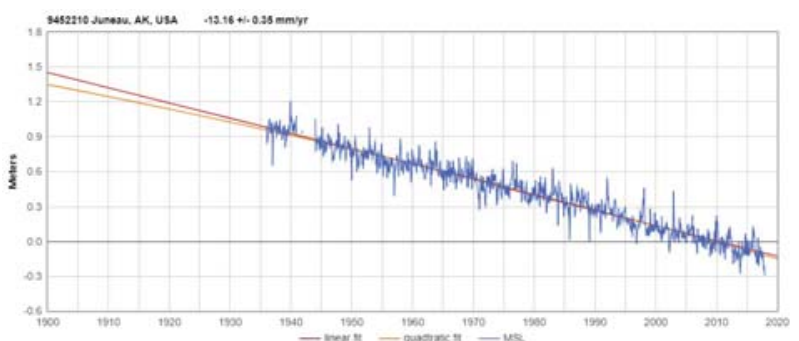

(a)

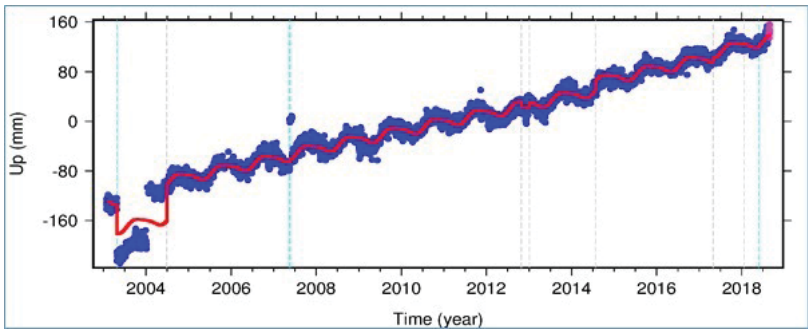

(b)

Figure 5: (a) MSL data for Juneau, AK, USA. Image reproduced modified after [4]. (b) GNSS time series for JNU1. Image reproduced modified after NGL.

The maximum and minimum subsidence rates are 17.745 and $14.820 \mathrm{~mm} / \mathrm{yr}$., respectively.

\subsection{Unalaska, AK, USA}

The MSL trend at Unalaska, AK, USA, Figure 6 , is $-4.14 \mathrm{~mm} / \mathrm{yr}$. with a $95 \%$ confidence interval of $\pm 0.38 \mathrm{~mm} / \mathrm{yr}$., based on MSL data from $1934 / 1$ to $2017 / 12$. The acceleration is $-0.01453 \pm 0.03414$ $\mathrm{mm} / \mathrm{yr}^{2}$.

The closest GNSS Station from SONEL is AV09 has an absolute vertical velocity of $3.50 \pm 0.30 \mathrm{~mm} / \mathrm{yr}$.

The distance-to-tide-gauge is $950 \mathrm{~m}$. According to JPL, AV09 has an absolute vertical velocity of $2.974 \pm 0.264$ mm/yr. According to NGL, AV09 (data 2004.3450 to 2018.4367) has an absolute vertical velocity of $3.779 \pm 1.247$ $\mathrm{mm} / \mathrm{yr}$.

A likely absolute vertical velocity for the tide gauge instrument is taken as the NGL value for AV09, of 3.779 $\mathrm{mm} / \mathrm{yr}$.

\subsection{Prince Rupert, Canada}

The MSL trend at Prince Rupert, Canada, Figure 7, is +1.17 $\mathrm{mm} / \mathrm{yr}$. with a $95 \%$ confidence interval of $\pm 0.23 \mathrm{~mm} / \mathrm{yr}$., based on MSL data from 1909/1 to 2016/12. The acceleration is $0.01484 \pm 0.01463 \mathrm{~mm} / \mathrm{yr}^{2}$. 


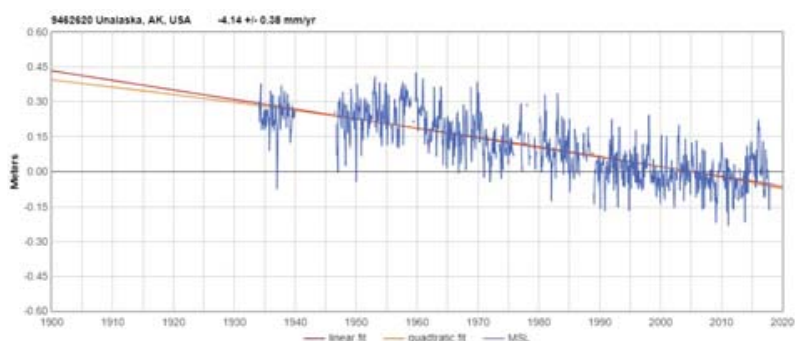

(a)

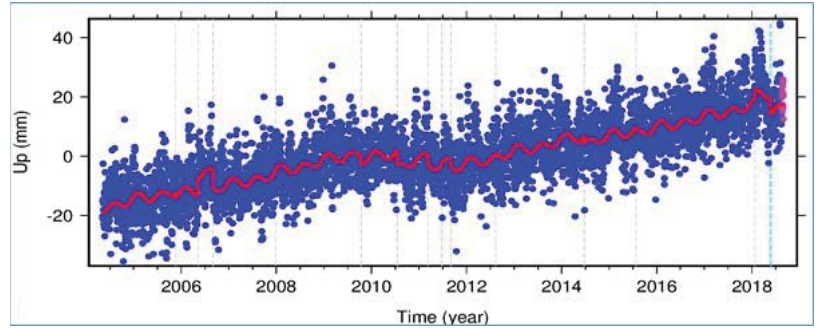

(b)

Figure 6: (a) MSL data for Unalaska, AK, USA. Image reproduced modified after [4]. (b) GNSS time series for AV09. Image reproduced modified after NGL.

$\mathrm{s}$

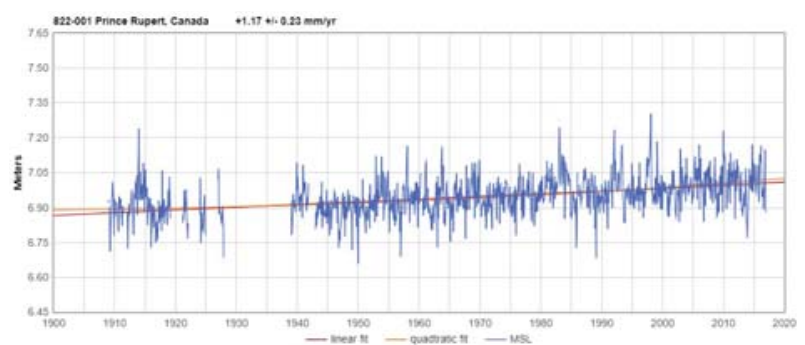

(a)

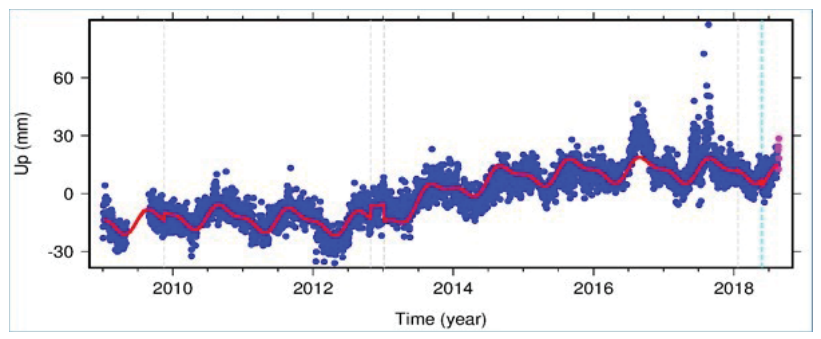

(b)

Figure 7: (a) MSL data for Prince Rupert, Canada. Image reproduced modified after [4]. (b) GNSS time series for BCPR. Image reproduced modified after NGL.

There is no nearby GNSS dome by SONEL. JPL has no nearby GNSS domes. NGL has the nearby the GNSS antennas of BCPT (data 2016.7201 to 2018.436) of absolute vertical velocity $2.760 \pm 4.392 \mathrm{~mm} / \mathrm{yr}$., BCPR (data 2009.0048 to 2018.4367 ) of absolute vertical velocity $1.369 \pm 1.015 \mathrm{~mm} / \mathrm{yr}$.
As the NGL value for BCPT suffers from large uncertainty, because of the short record, a likely absolute vertical velocity for the tide gauge instrument is taken as the NGL value for BCPR, of $1.369 \mathrm{~mm} / \mathrm{yr}$.

\subsection{Point Atkinson, Canada}

The MSL trend at Point Atkinson, Canada, Figure 8 , is $+0.95 \mathrm{~mm} / \mathrm{yr}$. with a $95 \%$ confidence interval of $\pm 0.24 \mathrm{~mm} / \mathrm{yr}$., based on MSL data from 1914/5 to 2016/12. The acceleration is $0.00531 \pm 0.01572 \mathrm{~mm} / \mathrm{yr}^{2}$

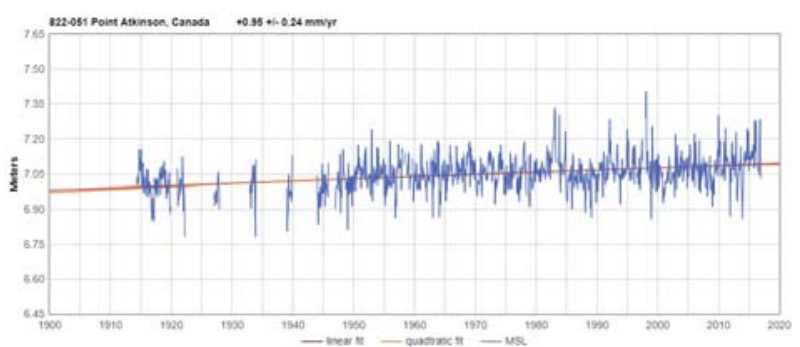

(a)

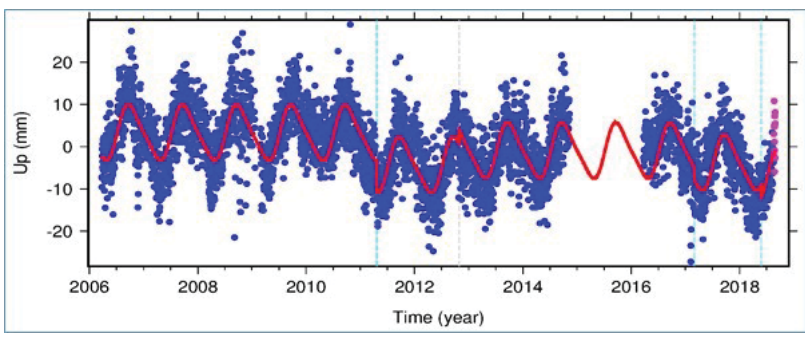

(b)

Figure 8: (a) MSL data for Point Atkinson, Canada. Image reproduced modified after [4]. (b) GNSS time series for P440. Image reproduced modified after NGL.

There is no nearby GNSS dome by SONEL. A rough estimation of the absolute vertical velocity of the tide gauge is taken as the JPL result for CHWK and CWAK, southeast of Vancouver, Canada, CHWK of absolute vertical velocity $1.149 \pm 0.455 \mathrm{~mm} / \mathrm{yr}$. CWAK of absolute vertical velocity $1.389 \pm 3.698 \mathrm{~mm} / \mathrm{yr}$., and P440, south of Vancouver, Canada, $\mathrm{P} 440$ of absolute vertical velocity $-1.196 \pm 0.583$ $\mathrm{mm} / \mathrm{yr}$.

Or, similarly, the result from NGL, CHWK (data 1998.8802 to 2018.4367) of absolute vertical velocity $1.162 \pm 0.656 \mathrm{~mm} / \mathrm{yr} ., \mathrm{P} 440$ (data 2006.2286 to 2018.4367 ) of absolute vertical velocity $-0.050 \pm 0.817 \mathrm{~mm} / \mathrm{yr}$. From the average of the NGL results, a likely absolute vertical velocity for the tide gauge instrument is taken as $0.556 \mathrm{~mm} / \mathrm{yr}$. The 
maximum and minimum subsidence rates are 1.162 and $0.050 \mathrm{~mm} / \mathrm{yr}$., respectively.

\subsection{Vancouver, Canada}

The MSL trend in Vancouver, Canada, Figure 9, is $+0.49 \mathrm{~mm} / \mathrm{yr}$. with a $95 \%$ confidence interval of $\pm 0.22 \mathrm{~mm} / \mathrm{yr}$., based on MSL data from 1909/11 to 2016/12. The acceleration is $0.0251 \pm 0.0141 \mathrm{~mm} / \mathrm{yr}^{2}$.

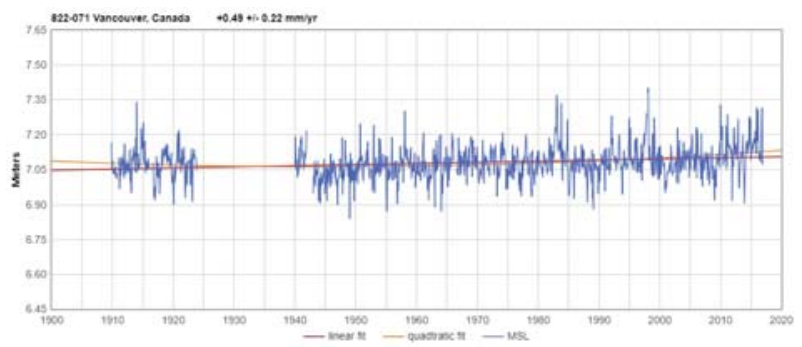

(a)

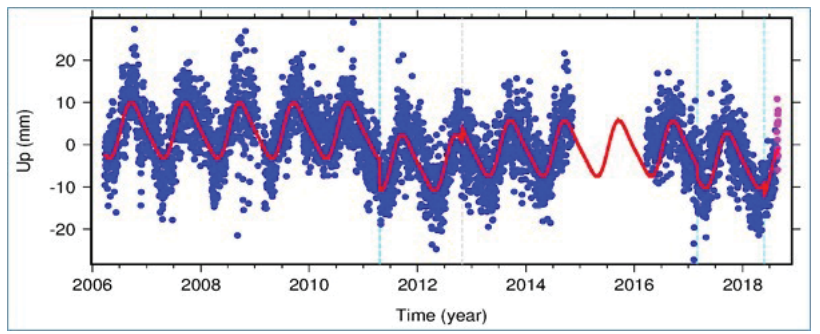

(b)

Figure 9: (a) MSL data for Vancouver, Canada. Image reproduced modified after [4]. (b) GNSS time series for P440. Image reproduced modified after NGL.

There is no nearby GNSS dome by SONEL.

As a rough estimation of the absolute vertical velocity of the tide gauge, the JPL result for CHWK and CWAK, southeast of Vancouver, Canada, and P440, south of Vancouver, Canada, or also the NGL results for CHWK and P440 are considered.

Same as Point Atkinson, Canada, from the average of the NGL results, a likely absolute vertical velocity for the tide gauge instrument is taken as $0.556 \mathrm{~mm} / \mathrm{yr}$. The maximum and minimum subsidence rates are 1.162 and -0.050 $\mathrm{mm} / \mathrm{yr}$. respectively.

\subsection{Victoria, Canada}

The MSL trend at Victoria, Canada, Figure 10, is $+0.73 \mathrm{~mm} / \mathrm{yr}$. with a $95 \%$ confidence in- terval of $\pm 0.19 \mathrm{~mm} / \mathrm{yr}$., based on MSL data from $1909 / 3$ to $2016 / 12$. The acceleration is $0.00663 \pm 0.01361 \mathrm{~mm} / \mathrm{yr}^{2}$.

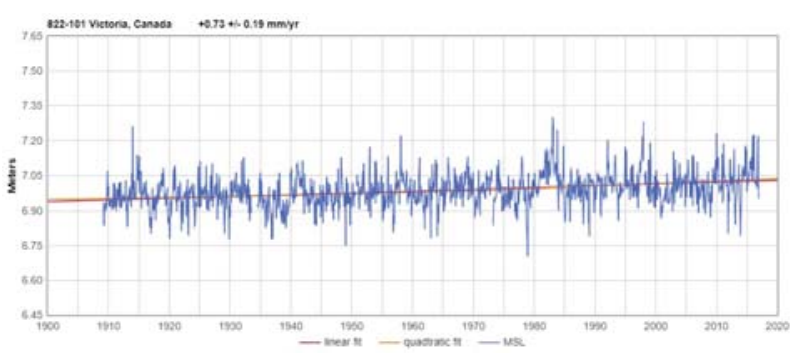

(a)

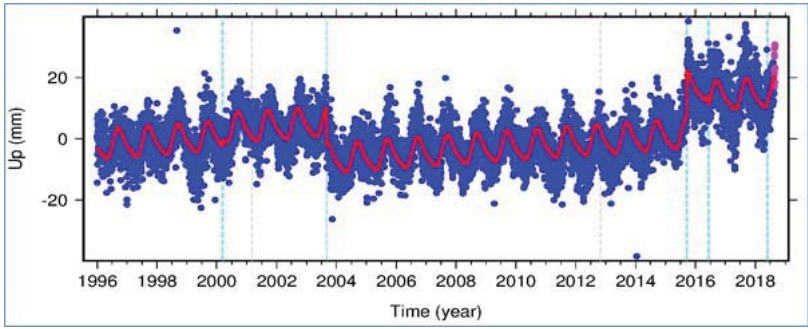

(b)

Figure 10: (a) MSL data for Victoria, Canada. Image reproduced modified after [4]. (b) GNSS time series for ALBH. Image reproduced modified after NGL.

The closest GNSS Station from SONEL is ALBH of absolute vertical velocity $0.64 \pm 0.14 \mathrm{~mm} / \mathrm{yr}$.

The distance-to-tide-gauge is $9,431 \mathrm{~m}$. According to JPL, ALBH has absolute vertical velocity $0.17 \pm 0.215 \mathrm{~mm} / \mathrm{yr}$.

According to NGL, ALBH (data 1996.0000 to 2018.4367) has absolute vertical velocity $0.818 \pm 0.472$ $\mathrm{mm} / \mathrm{yr}$.

From the NGL result for ALBH, the absolute vertical velocity of the tide gauge is taken as $+0.818 \mathrm{~mm} / \mathrm{yr}$.

\subsection{Tofino, Canada}

The MSL trend at Tofino, Canada, Figure 11, is $-1.26 \mathrm{~mm} / \mathrm{yr}$. with a $95 \%$ confidence interval of $\pm 0.27 \mathrm{~mm} / \mathrm{yr}$., based on MSL data from 1909/10 to 2016/12. The acceleration is $0.01998 \pm 0.01699 \mathrm{~mm} / \mathrm{yr}^{2}$.

The closest GNSS Stations from SONEL are TFNO has an absolute vertical velocity of $1.19 \pm 0.47 \mathrm{~mm} / \mathrm{yr}$.

UCLU has an absolute vertical velocity of $2.99 \pm 0.19$ $\mathrm{mm} / \mathrm{yr}$. TFNO has a distance-to-tide-gauge of $343 \mathrm{~m}$, UCLU has a distance-to-tide-gauge of $37,070 \mathrm{~m}$. 


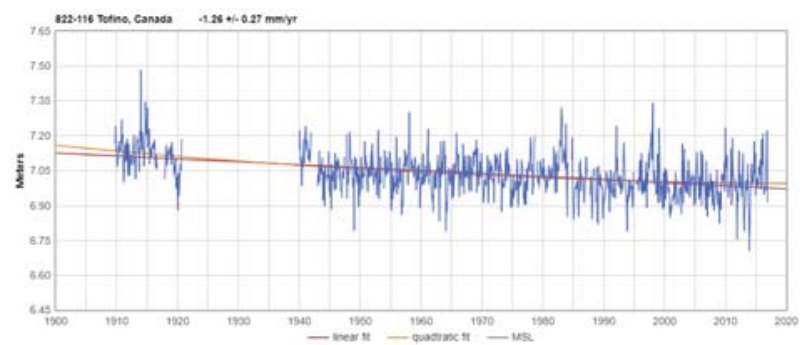

(a)

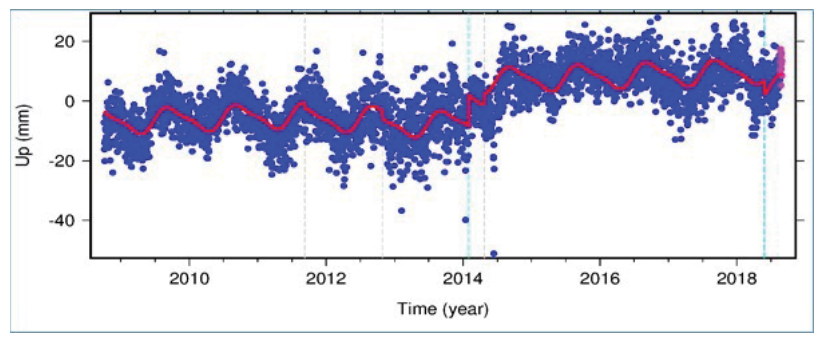

(b)

Figure 11: (a) MSL data for Tofino, Canada. Image reproduced modified after [4]. (b) GNSS time series for TFNO. Image reproduced modified after NGL. This GNSS antenna is almost co-located with the tide gauge.

According to JPL, TFNO has absolute vertical velocity $4.482 \pm 1.418 \mathrm{~mm} / \mathrm{yr}$., UCLU has an absolute vertical velocity of $2.186 \pm 0.401 \mathrm{~mm} / \mathrm{yr}$.

According to NGL, TFNO (data 2008.7584 to 2018.4367) has absolute vertical velocity $0.716 \pm 1.028 \mathrm{~mm} / \mathrm{yr}$., UCLU (data 1996.0000 to 2018.4367 ) has absolute vertical velocity $2.116 \pm 0.570 \mathrm{~mm} / \mathrm{yr}$.

From the NGL results for TFNO, which is almost colocated with the tide gauge, the absolute vertical velocity of the tide gauge is taken as $+0.716 \mathrm{~mm} / \mathrm{yr}$.

\subsection{Friday Harbor, WA, USA}

The MSL trend at Friday Harbor, WA, USA, Figure 12, is $+1.20 \mathrm{~mm} / \mathrm{yr}$. with a $95 \%$ confidence interval of $\pm 0.27 \mathrm{~mm} / \mathrm{yr}$., based on MSL data from $1934 / 1$ to 2017/12. The acceleration is $0.01018 \pm 0.02539 \mathrm{~mm} / \mathrm{yr}^{2}$.

The nearby GNSS Station from SONEL is SCO2 has absolute vertical velocity $0.23 \pm 0.24 \mathrm{~mm} / \mathrm{yr}$.

The distance-to-tide-gauge is $359 \mathrm{~m}$. According to JPL, SC02 has absolute vertical velocity $-0.2 \pm 0.155 \mathrm{~mm} / \mathrm{yr}$.

Aaccording to NGL SCO2 (data 2001.8617 to 2018.4367) has absolute vertical velocity $+0.192 \pm 2.887 \mathrm{~mm} / \mathrm{yr}$.

From the NGL results for SCO2, the absolute vertical velocity of the tide gauge is taken as $+0.192 \mathrm{~mm} / \mathrm{yr}$.

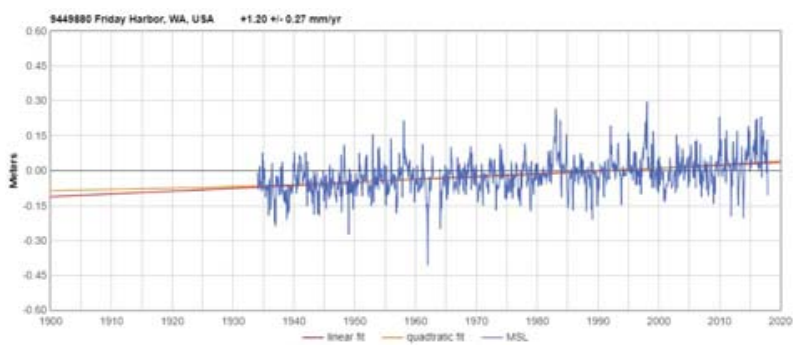

(a)

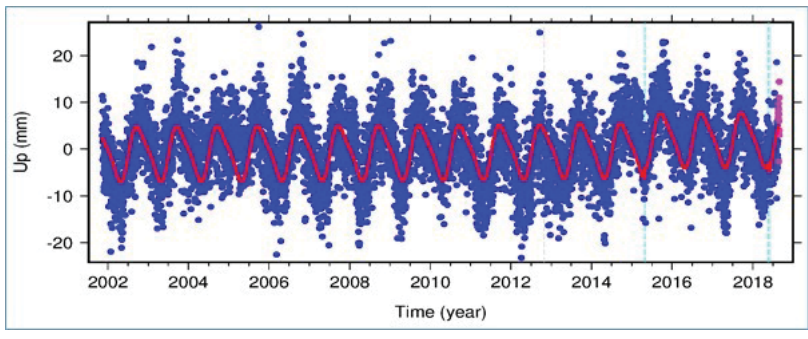

(b)

Figure 12: (a) MSL data for Friday Harbor, WA, USA. Image reproduced modified after [4]. (b) GNSS time series for SC02. Image reproduced modified after NGL. This GNSS antenna is almost colocated with the tide gauge.

\subsection{Seattle, WA, USA}

The MSL trend at Seattle, WA, USA, Figure 13, is $+2.05 \mathrm{~mm} / \mathrm{yr}$. with a $95 \%$ confidence interval of $\pm 0.15 \mathrm{~mm} / \mathrm{yr}$., based on MSL data from $1899 / 1$ to $2017 / 12$. The acceleration is $0.00987 \pm 0.00986 \mathrm{~mm} / \mathrm{yr}^{2}$.

The closest GNSS Stations from SONEL are: SMAI, with no data, SEAT of absolute vertical velocity $-0.99 \pm 0.22$ $\mathrm{mm} / \mathrm{yr}$., SSHO with no data.

SMAI has distance-to-tide-gauge of 8,690 m, SEAT has distance-to-tide-gauge of 5,900 m, has SSHO distance-totide-gauge of 10,520 m.

According to JPL, SMAI has absolute vertical velocity $-2.478 \pm 0.601 \mathrm{~mm} / \mathrm{yr}$., SEAT has absolute vertical velocity $1.668 \pm 0.156 \mathrm{~mm} / \mathrm{yr}$.

According to NGL SMAI (data 2002.8309 to 2018.436) has absolute vertical velocity $-0.887 \pm 0.708 \mathrm{~mm} / \mathrm{yr}$., SEAT (data 1996.0000 to 2018.4367 ) has absolute vertical velocity $-0.774 \pm 0.556 \mathrm{~mm} / \mathrm{yr} .$, SSHO (data 2002.83092018 .4367 ) has absolute vertical velocity $-0.552 \pm 0.829 \mathrm{~mm} / \mathrm{yr}$.

From all the NGL results, the absolute vertical velocity of the tide gauge is taken as $-0.738 \mathrm{~mm} / \mathrm{yr}$.

\subsection{Neah Bay, WA, USA}

The MSL trend at Neah Bay, WA, USA, Figure 14, is $-1.69 \mathrm{~mm} / \mathrm{yr}$. with a $95 \%$ confidence interval of 


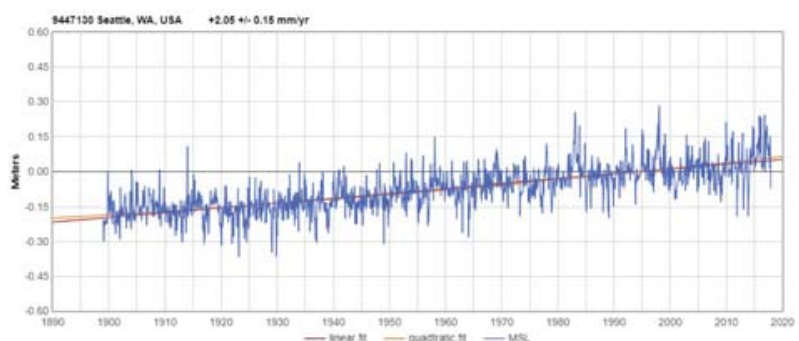

(a)

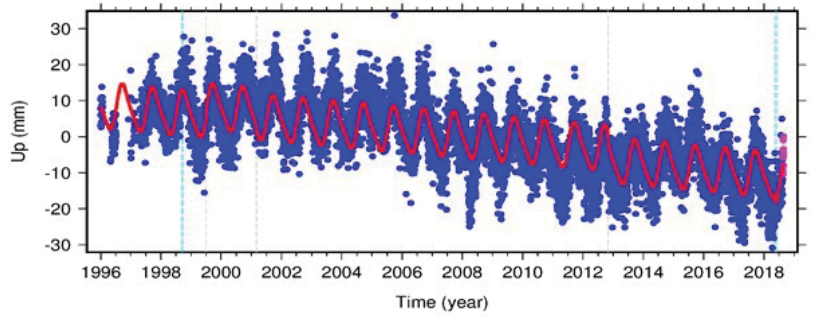

(b)

Figure 13: (a) MSL data for Seattle, WA, USA. Image reproduced modified after [4]. (b) GNSS time series for SEAT. Image reproduced modified after NGL.

$\pm 0.30 \mathrm{~mm} / \mathrm{yr}$., based on MSL data from 1934/8 to 2017/12. The acceleration is $-0.01619 \pm 0.02760 \mathrm{~mm} / \mathrm{yr}^{2}$.

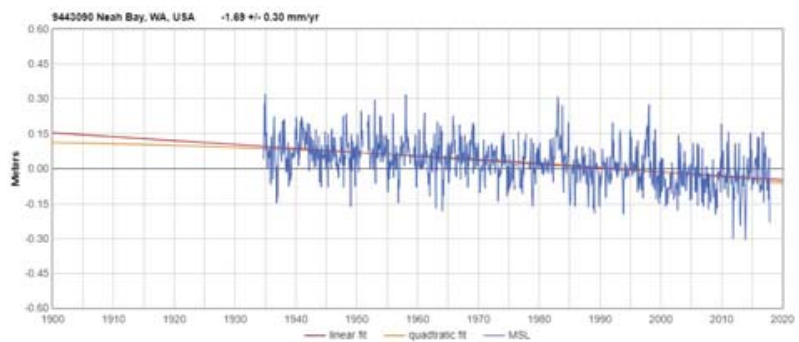

(a)

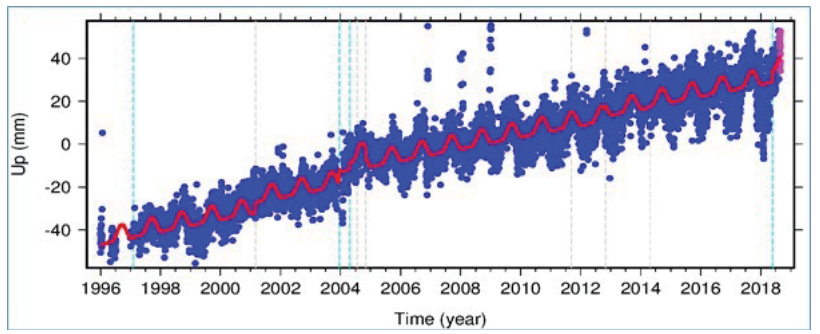

(b)

Figure 14: (a) MSL data for Neah Bay, WA, USA. Image reproduced modified after [4]. (b) GNSS time series for NEAH. Image reproduced modified after NGL.

The closest GNSS Station from SONEL is NEAH of absolute vertical velocity of $3.25 \pm 0.29 \mathrm{~mm} / \mathrm{yr}$.
The distance-to-tide-gauge is $7,776 \mathrm{~m}$.

According to JPL NEAH has absolute vertical velocity $2.641 \pm 0.215 \mathrm{~mm} / \mathrm{yr}$.

According to NGL NEAH (data 1996.0000 to 2018.4367) has absolute vertical velocity $2.885 \pm 0.622 \mathrm{~mm} / \mathrm{yr}$.

From the NGL results for NEAH, the absolute vertical velocity of the tide gauge is taken as $+2.885 \mathrm{~mm} / \mathrm{yr}$.

\subsection{Astoria, OR, USA}

The MSL trend at Astoria, OR, USA, Figure 15, is $0.14 \mathrm{~mm} / \mathrm{yr}$. with a $95 \%$ confidence interval of $\pm 0.33 \mathrm{~mm} / \mathrm{yr}$., based on MSL data from 1925/2 to 2017/12. The acceleration is $0.01480 \pm 0.02760 \mathrm{~mm} / \mathrm{yr}^{2}$.

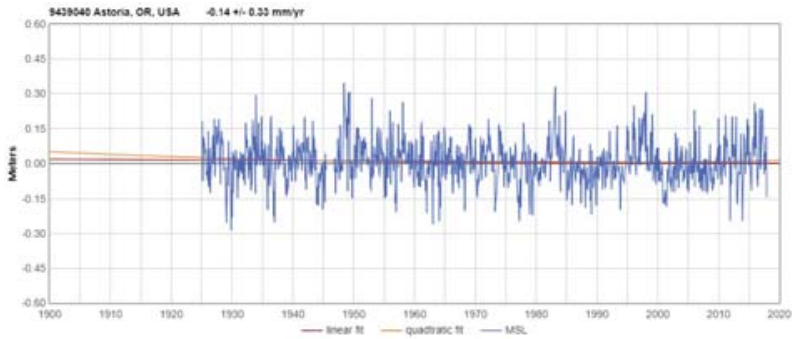

(a)

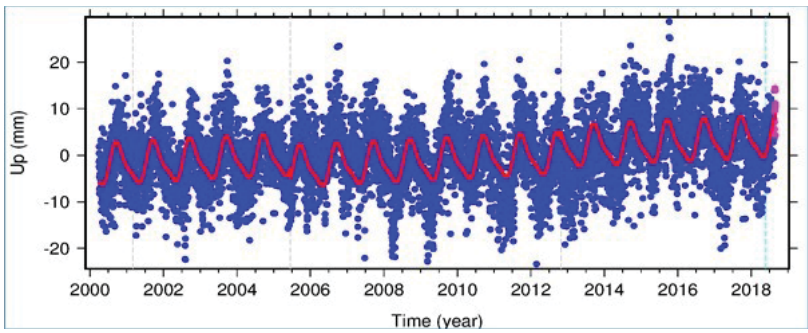

(b)

Figure 15: (a) MSL data for Astoria, OR, USA. Image reproduced modified after [4]. (b) GNSS time series for TPW2. Image reproduced modified after NGL. This GNSS antenna is almost co-located with the tide gauge.

The closest GNSS Stations from SONEL are FTS 5 of absolute vertical velocity $1.29 \pm 0.37 \mathrm{~mm} / \mathrm{yr}$., TPW2 of absolute vertical velocity $0.35 \pm 0.15 \mathrm{~mm} / \mathrm{yr}$., FTS1 of absolute vertical velocity $2.58 \pm 0.27 \mathrm{~mm} / \mathrm{yr}$.

FTS5 has a distance-to-tide-gauge of $14,455 \mathrm{~m}$, TPW2 has distance-to-tide-gauge of $2 \mathrm{~m}$, FTS1 has distance-totide-gauge of 14,462 m.

According to JPL FST1 has absolute vertical velocity $-1.195 \pm 2.086 \mathrm{~mm} / \mathrm{yr}$., FST2 has absolute vertical velocity $0.94 \pm 3.672 \mathrm{~mm} / \mathrm{yr}$., TPW2 has absolute vertical velocity $0.288 \pm 0.448 \mathrm{~mm} / \mathrm{yr}$. 
According to NGL, FST1 (data 2000.6242 to 2007.9425) has absolute vertical velocity $-3.624 \pm 0.802 \mathrm{~mm} / \mathrm{yr}$., FST2 (data 2000.6242 to 2007.9370) has absolute vertical velocity $-0.954 \pm 0.541 \mathrm{~mm} /$ yr., FST5 (data 2007.9316 to 2016.5914) has absolute vertical velocity $-1.623 \pm 0.758 \mathrm{~mm} / \mathrm{yr}$., TPW2 (data 2000.2464 to 2018.4367) has absolute vertical velocity $0.340 \pm 0.628 \mathrm{~mm} / \mathrm{yr}$.

From the NGL results for TPW2, which is co-located with the tide gauge, the absolute vertical velocity of the tide gauge is taken as $+0.340 \mathrm{~mm} / \mathrm{yr}$.

\subsection{Crescent City, CA, USA}

The MSL trend at Crescent City, CA, USA, Figure 16, is $-0.78 \mathrm{~mm} / \mathrm{yr}$. with a $95 \%$ confidence interval of $\pm 0.30 \mathrm{~mm} / \mathrm{yr}$., based on MSL data from 1933/1 to 2017/12. The acceleration is $-0.00857 \pm 0.02672 \mathrm{~mm} / \mathrm{yr}^{2}$.

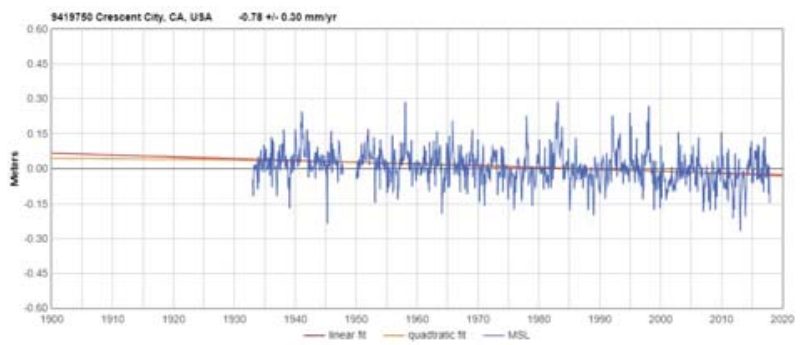

(a)

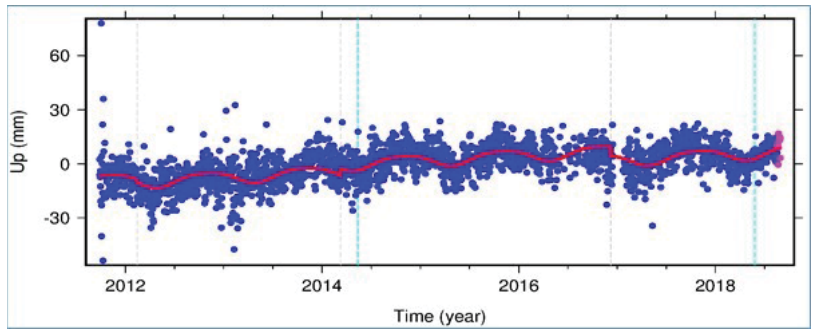

(b)

Figure 16: (a) MSL data for Crescent City, CA, USA. Image reproduced modified after [4]. (b) GNSS time series for CACC. Image reproduced modified after NGL. This GNSS antenna is almost colocated with the tide gauge.

The closest GNSS Stations from SONEL are PTSG of absolute vertical velocity $3.19 \pm 0.17 \mathrm{~mm} / \mathrm{yr}$. , CACC of signal bot robust.

CACC has a distance-to-tide-gauge of $2 \mathrm{~m}$, while PTSG has a distance-to-tide-gauge of 7,195 m.

According to JPL PTSG has an absolute vertical velocity of $1.88 \pm 0.363 \mathrm{~mm} / \mathrm{yr}$.
According to NGL PTSG (data 1999.8193 to 2018.4367) has absolute vertical velocity $4.394 \pm 0.835 \mathrm{~mm} / \mathrm{yr}$. and CACC (data 2011.7372 to 2018.4367) has absolute vertical velocity $2.790 \pm 1.426 \mathrm{~mm} / \mathrm{yr}$.

From the NGL result for CACC, which is co-located with the tide gauge, the absolute vertical velocity of the tide gauge is taken as $+2.790 \mathrm{~mm} / \mathrm{yr}$.

\subsection{San Francisco, CA, USA}

The MSL trend at San Francisco, CA, USA, Figure 17, is $+1.47 \mathrm{~mm} / \mathrm{yr}$. with a $95 \%$ confidence interval of $\pm 0.13 \mathrm{~mm} / \mathrm{yr}$., based on MSL data from 1854/7 to 2017/12. The acceleration is $0.01406 \pm 0.00619 \mathrm{~mm} / \mathrm{yr}^{2}$.

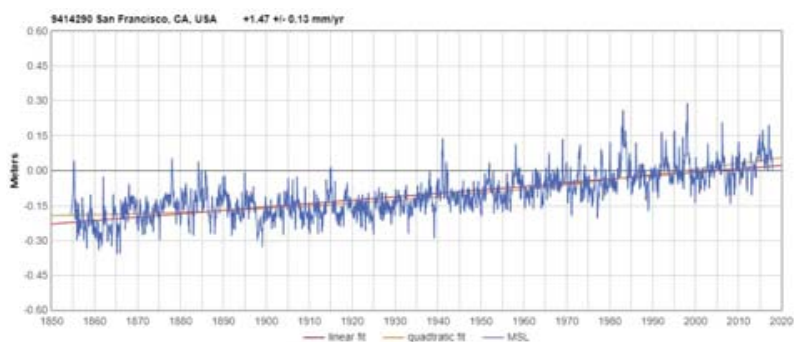

(a)

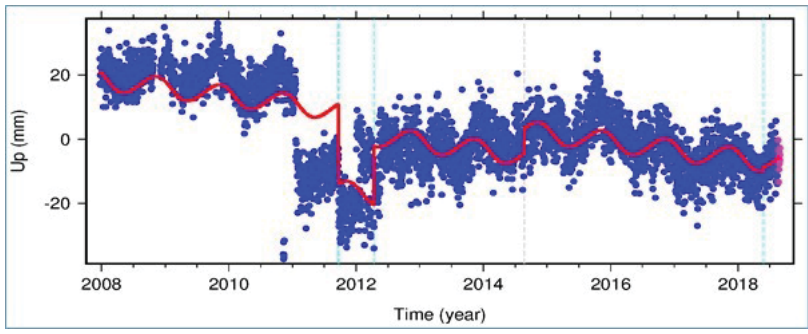

(b)

Figure 17: (a) MSL data for San Francisco, CA, USA. Image reproduced modified after [4]. (b) GNSS time series for UCSF. Image reproduced modified after NGL.

The closest GNSS Stations from SONEL are SBRB of signal not robust, UCSF of signal not robust, PBL1 of absolute vertical velocity $-0.84 \pm 0.21 \mathrm{~mm} / \mathrm{yr}$., TIBB of absolute vertical velocity $-0.04 \pm 0.15 \mathrm{~mm} / \mathrm{yr}$., SBRN of absolute vertical velocity $-0.51 \pm 0.71 \mathrm{~mm} / \mathrm{yr}$.

SBRB has a distance-to-tide-gauge of $14,210 \mathrm{~m}$, UCSF has a distance-to-tide-gauge of 4,850 m, PBL1 has distance-to-tide-gauge of $6,500 \mathrm{~m}$, TIBB has distanceto-tide-gauge of 9,551 $\mathrm{m}$ and SBRN has Distance to Tide $14,235 \mathrm{~m}$.

According to JPL SBRB has absolute vertical velocity $-0.758 \pm 0.832 \mathrm{~mm} / \mathrm{yr}$., UCSF has absolute vertical velocity - 
$3.34 \pm 0.733 \mathrm{~mm} / \mathrm{yr}$., PBL1 has an absolute vertical velocity of $0.358 \pm 0.75 \mathrm{~mm} / \mathrm{yr}$., TIBB has absolute vertical velocity $-0.891 \pm 0.189 \mathrm{~mm} / \mathrm{yr}$., SBRN has absolute vertical velocity $-1.88 \pm 1.006 \mathrm{~mm} / \mathrm{yr}$.

According to NGL, UCSF (data 2007.9726 to 2018.4367) has absolute vertical velocity $-2.528 \pm 0.936 \mathrm{~mm} / \mathrm{yr}$., SBRB (data 2008.6461 to 2018.4367) has absolute vertical velocity $-1.085 \pm 1.263 \mathrm{~mm} / \mathrm{yr}$., SBRN (data 2003.1759 to 2011.1595) has absolute vertical velocity $-1.526 \pm 1.667 \mathrm{~mm} / \mathrm{yr}$., PBL1 (data 1996.0301 to 2004.1834) has absolute vertical velocity $-0.867 \pm 0.756 \mathrm{~mm} / \mathrm{yr}$., TIBB (data 1996.0000 to 2018.4367) has absolute vertical velocity $-1.233 \pm 0.652$ $\mathrm{mm} / \mathrm{yr}$.

From all the NGL results, the absolute vertical velocity of the tide gauge is taken as $-1.448 \mathrm{~mm} / \mathrm{yr}$.

Maximum and minimum are -0.867 and $-2.528 \mathrm{~mm} / \mathrm{yr}$. respectively.

\subsection{Santa Monica, CA, USA}

The MSL trend at Santa Monica, CA, USA, Figure 18, is $+1.52 \mathrm{~mm} / \mathrm{yr}$. with a $95 \%$ confidence interval of $\pm 0.33 \mathrm{~mm} / \mathrm{yr}$., based on MSL data from 1933/1 to 2017/12. The acceleration is $-0.00718 \pm 0.03198 \mathrm{~mm} / \mathrm{yr}^{2}$.

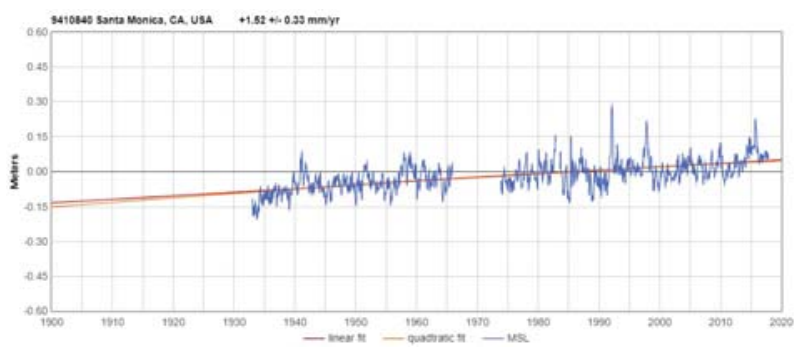

(a)

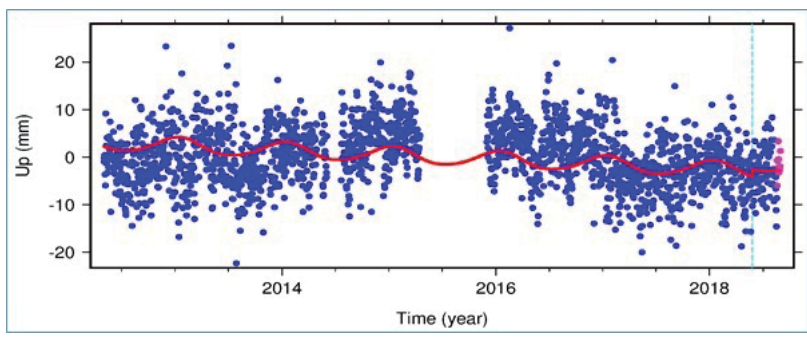

(b)

Figure 18: (a) MSL data for Santa Monica, CA, USA. Image reproduced modified after [4]. (b) GNSS time series for CASM. Image reproduced modified after NGL.

The closest GNSS Station from SONEL is WRHS, of absolute vertical velocity $1.56 \pm 0.10 \mathrm{~mm} / \mathrm{yr}$.
The distance-to-tide-gauge is $8,615 \mathrm{~m}$.

However, much closer is the GNSS antenna of CASM, distance-to-tide-gauge of 2,816 m.

According to JPL, WRHS has absolute vertical velocity $2.057 \pm 0.424 \mathrm{~mm} / \mathrm{yr}$.

According to NGL WRHS (data 1999.7700 to 2018.4367) has absolute vertical velocity $0.716 \pm 0.628 \mathrm{~mm} / \mathrm{yr}$., CASM (data 2012.3368 to 2018.4367) has absolute vertical velocity $-0.927 \pm 1.004 \mathrm{~mm} / \mathrm{yr}$.

From the NGL results for CASM, that is much closer to the tide gauge even if not exactly co-located, the absolute vertical velocity of the tide gauge is taken as $-0.927 \mathrm{~mm} / \mathrm{yr}$.

This result makes the Santa Monica result consistent with the nearby tide gauge patterns and subsidence data.

\subsection{Los Angeles, CA, USA}

The MSL trend at Los Angeles, CA, USA, Figure 19, is $+0.99 \mathrm{~mm} / \mathrm{yr}$. with a $95 \%$ confidence interval of $\pm 0.24 \mathrm{~mm} / \mathrm{yr}$., based on MSL data from 1923/12 to 2017/12. The acceleration is $0.01773 \pm 0.01924 \mathrm{~mm} / \mathrm{yr}^{2}$.

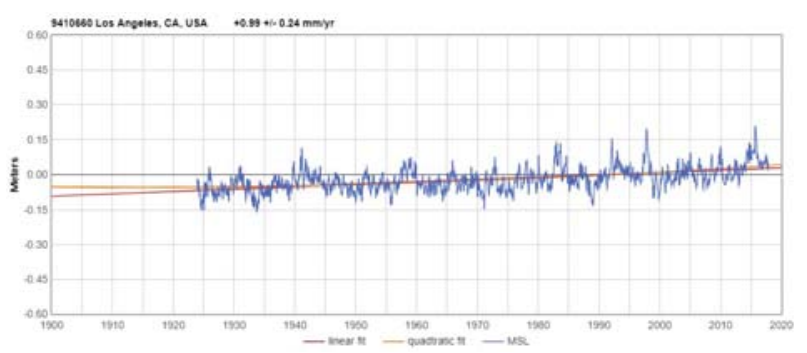

(a)

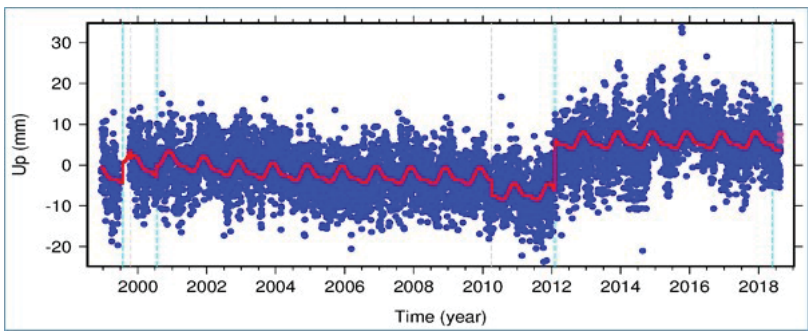

(b)

Figure 19: (a) MSL data for Los Angeles, CA, USA. Image reproduced modified after [4]. (b) GNSS time series for VTIS. Image reproduced modified after NGL.

The closest GNSS Stations from SONEL are CRHS of no data, TORP of no data, VTIS of absolute vertical velocity $-0.15 \pm 0.14 \mathrm{~mm} / \mathrm{yr}$.

CRHS is far from the tide gauge, at a distance-to-tidegauge of $11,430 \mathrm{~m}$. 
VTIS is closer, at distance-to-tide-gauge of 2,168 m. TORP is mid-way at distance-to-tide-gauge of 10,230 m.

According to JPL CRHS has absolute vertical velocity $0.212 \pm 0.623 \mathrm{~mm} / \mathrm{yr}$., TORP has absolute vertical velocity $0.347 \pm 0.198 \mathrm{~mm} / \mathrm{yr}$., VTIS has absolute vertical velocity $0.652 \pm 0.324 \mathrm{~mm} / \mathrm{yr}$.

According to NGL, CRHS (data 1999.3949 to 2018.4367) has absolute vertical velocity $-1.248 \pm 0.637 \mathrm{~mm} / \mathrm{yr}$., TORP (data 1997.1608 to 2018.4367) has absolute vertical velocity $-0.479 \pm 0.498 \mathrm{~mm} / \mathrm{yr}$., VTIS (data 1998.9377 to 2018.4367 ) has absolute vertical velocity $-0.477 \pm 0.526 \mathrm{~mm} / \mathrm{yr}$.

From all the NGL results, the absolute vertical velocity of the tide gauge is taken as $-0.735 \mathrm{~mm} / \mathrm{yr}$.

Maximum and minimum are -0.477 and $-1.248 \mathrm{~mm} / \mathrm{yr}$. respectively.

\subsection{La Jolla, CA, USA}

The MSL trend at La Jolla, CA, USA, Figure 20, is $+2.15 \mathrm{~mm} / \mathrm{yr}$. with a $95 \%$ confidence interval of $\pm 0.26 \mathrm{~mm} / \mathrm{yr}$., based on MSL data from $1924 / 11$ to $2017 / 12$. The acceleration is $0.01121 \pm 0.02154 \mathrm{~mm} / \mathrm{yr}^{2}$.

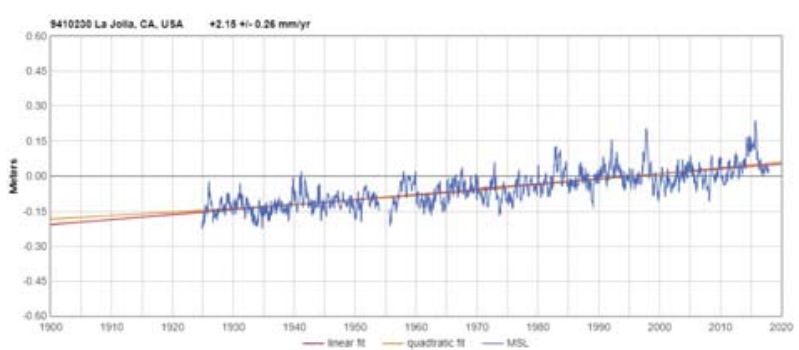

(a)

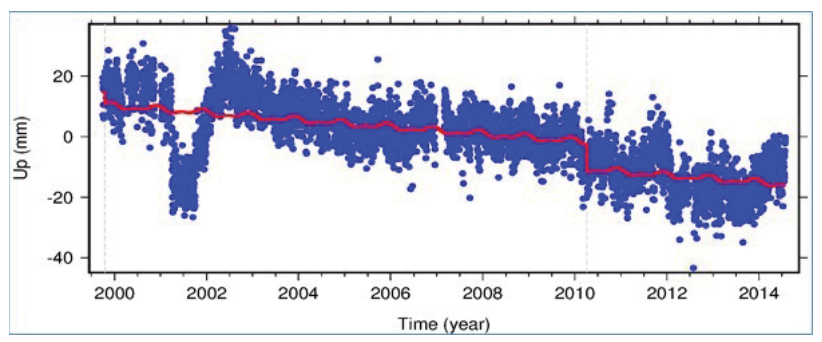

(b)

Figure 20: (a) MSL data for La Jolla, CA, USA. Image reproduced modified after [4]. (b) GNSS time series for SPW2. Image reproduced modified after NGL. This GNSS antenna is almost co-located with the tide gauge.

The closest GNSS Stations indicated by SONEL are SPW2 of no data, SIO5 of no data, SIO3 of absolute vertical velocity $0.70 \pm 0.38 \mathrm{~mm} / \mathrm{yr}$.
The distance-to-tide-gauge is only $3 \mathrm{~m}$ (SPW2) or about 600-700 m (SIO3), or 2,990 m (SIO5).

According to JPL SIO2 has absolute vertical velocity $1.519 \pm 4.303 \mathrm{~mm} / \mathrm{yr} .$, SIO3 has absolute vertical velocity $0.96 \pm 0.672 \mathrm{~mm} / \mathrm{yr}$., SIO5 has absolute vertical velocity $1.556 \pm 0.569 \mathrm{~mm} / \mathrm{yr}$.

According to NGL, SIO3 (data 1996.0000 to 2012.1834) has absolute vertical velocity $0.122 \pm 0.594 \mathrm{~mm} / \mathrm{yr}$., SIO5 (data 2002.3710 to 2018.4367) has absolute vertical velocity $-1.049 \pm 0.545 \mathrm{~mm} / \mathrm{yr}$., SPW2 (data 1999.7454 to 2014.5736) has absolute vertical velocity $-1.795 \pm 0.753 \mathrm{~mm} / \mathrm{yr}$.,

From the NGL result for SPW2, which is practically colocated with the tide gauge, the absolute vertical velocity of the tide gauge is taken as $-1.795 \mathrm{~mm} / \mathrm{yr}$.

\subsection{San Diego, CA, USA}

The MSL trend at San Diego, CA, USA, Figure 21, is $+2.17 \mathrm{~mm} / \mathrm{yr}$. with a $95 \%$ confidence interval of $\pm 0.19 \mathrm{~mm} / \mathrm{yr}$., based on MSL data from 1906/1 to 2017/12. The acceleration is $0.00813 \pm 0.01279 \mathrm{~mm} / \mathrm{yr}^{2}$.

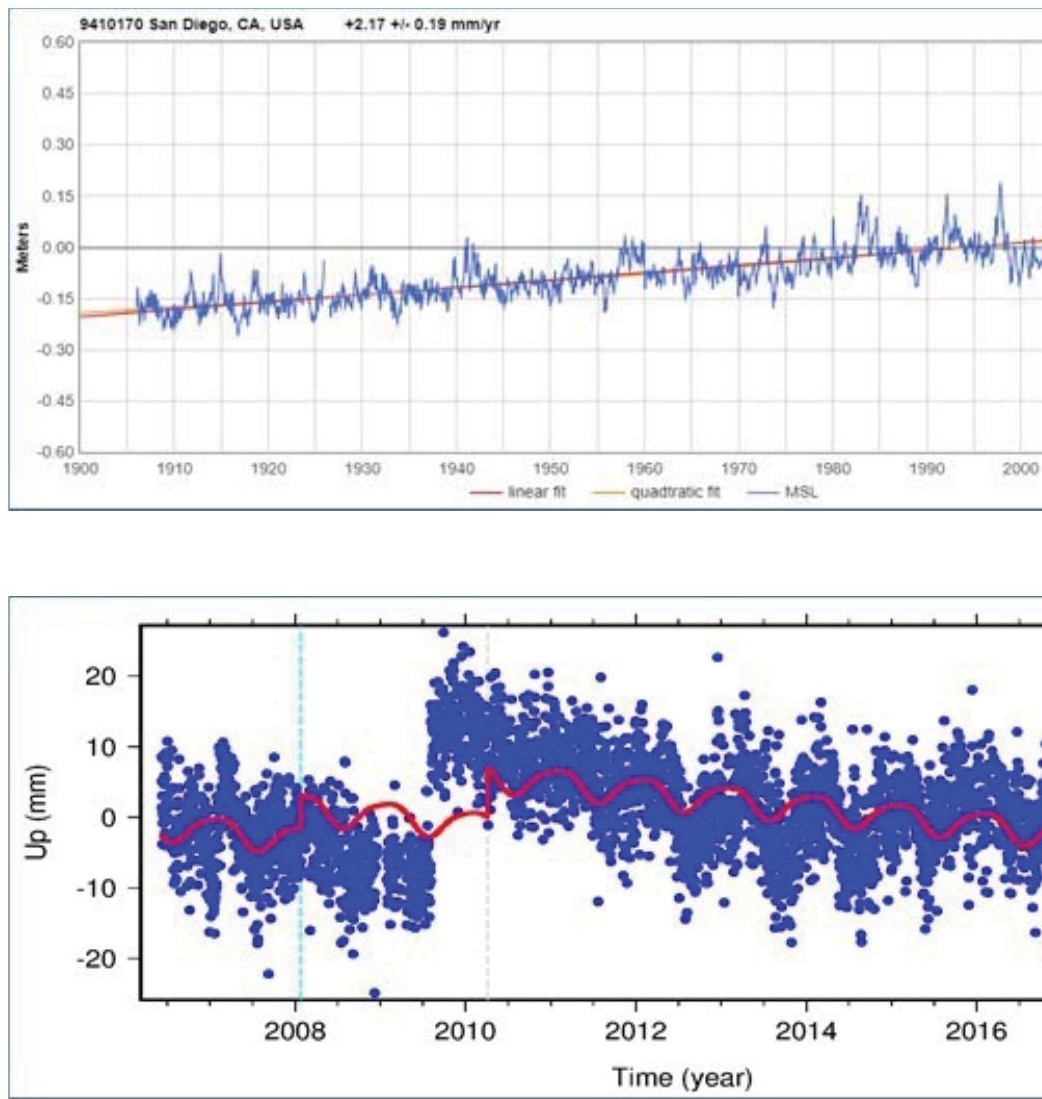




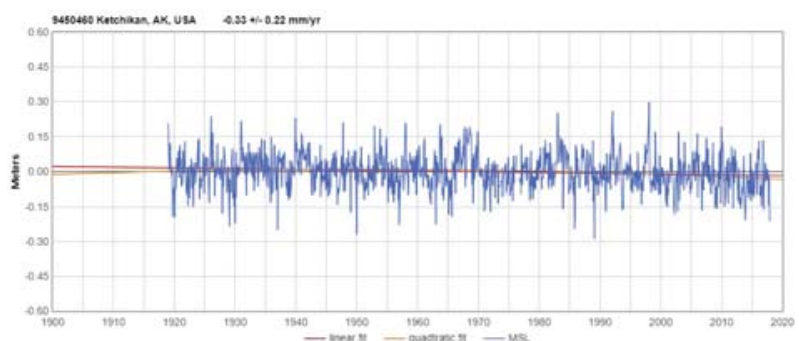

(a)

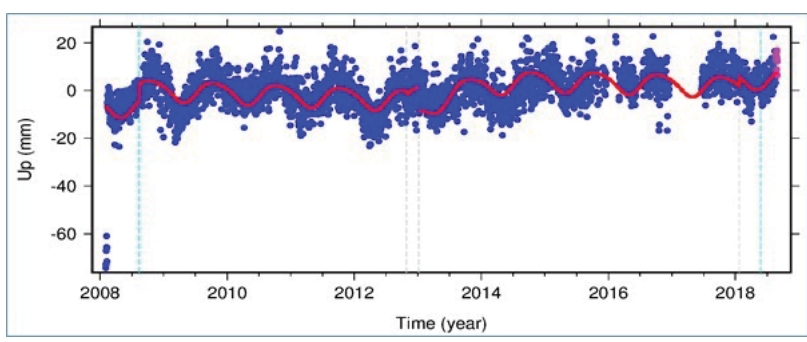

(b)

Figure 21: (a) MSL data for San Diego, CA, USA. Image reproduced modified after [4]. (b) GNSS time series for PL05. Image reproduced modified after NGL.

GNSS antennas, active or decommissioned, are in Point Loma, on the other side of the bay, at a distance-totide-gauge of about $8,400 \mathrm{~m}$.

The closest GNSS Stations indicated by SONEL are P475 (no data), PLO6 (no data), PLO3, of absolute vertical velocity $-0.99 \pm 0.32 \mathrm{~mm} / \mathrm{yr}$. and PLO5, of absolute vertical velocity $-2.62 \pm 0.19 \mathrm{~mm} / \mathrm{yr}$.

According to JPL P475 has absolute vertical velocity $0.136 \pm 0.43 \mathrm{~mm} / \mathrm{yr}$., PLO3 has absolute vertical velocity $2.528 \pm 1.032 \mathrm{~mm} / \mathrm{yr}$.

According to NGL, P475 (data 2007.6003 to 2018.4367) has absolute vertical velocity $-1.021 \pm 0.719 \mathrm{~mm} / \mathrm{yr}$., PLO3 (data 1996.9391 to 2006.5133) has absolute vertical velocity $-2.391 \pm 0.744 \mathrm{~mm} / \mathrm{yr}$., PLO5 (data 2006.4339 to 2018.4367) has absolute vertical velocity $-1.874 \pm 0.654 \mathrm{~mm} / \mathrm{yr}$., PLO6 (data 2006.5435 to 2018.4367) has absolute vertical velocity $-1.779 \pm 0.763 \mathrm{~mm} / \mathrm{yr}$.

From all the NGL results, the absolute vertical velocity of the tide gauge is taken as $-1.766 \mathrm{~mm} / \mathrm{yr}$. maximum and minimum are -1.021 and $-2.391 \mathrm{~mm} / \mathrm{yr}$. respectively.

\subsection{Balboa, Panama}

The MSL trend at Balboa, Panama, Figure 22, is +1.44 $\mathrm{mm} / \mathrm{yr}$. with a $95 \%$ confidence interval of $\pm 0.21 \mathrm{~mm} / \mathrm{yr}$., based on MSL data from 1908/1 to 2017/12. The acceleration is $-0.00548 \pm 0.01504 \mathrm{~mm} / \mathrm{yr}^{2}$.

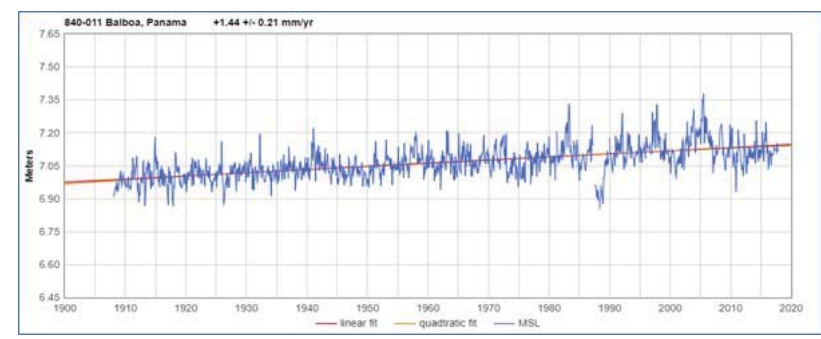

(a)

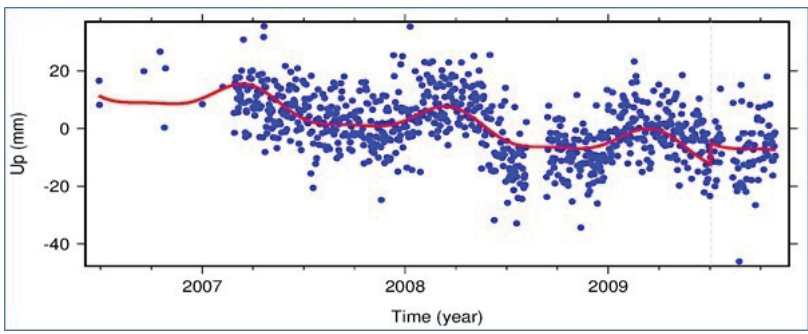

(b)

Figure 22: (a) MSL data for Balboa, Panama. Image reproduced modified after [4].

The closest GNSS Station indicated by SONEL is IGN1, distance-to-tide-gauge of 4,639 m, but no data. JPL has no stations. Per NGL, IGN1 (data 2008.5749 to 2018.4367) has absolute vertical velocity $0.908 \pm 1.630 \mathrm{~mm} / \mathrm{yr}$., PMPA (data 2006.4914 to 2009.8234) has absolute vertical velocity $-7.708 \pm 2.415 \mathrm{~mm} / \mathrm{yr}$.

PMPA is closer to the tide gauge.

From all the NGL results, the absolute vertical velocity of the tide gauge is taken as $-3.400 \mathrm{~mm} / \mathrm{yr}$. maximum and minimum are 0.908 and $-7.708 \mathrm{~mm} / \mathrm{yr}$., respectively.

\section{Discussion}

Table 1 and Figure 23 present a summary of the sea level and GNSS results for the LTT stations of West North America. $u$ is the relative sea-level rise, $w$ is the absolute vertical velocity at the GNSS antenna nearby the tide gauge, and $u=v+w$ is the absolute sea-level rise. The table also proposes as $w^{*}$ the Glacial Isostatic Adjustment (GIA) vertical velocities VM2 from [13, 14].

The GIA correction does not appear reasonable. Glacial isostatic models are of little help here to understand the absolute sea level rises, suggesting on average an uplift velocity of $-0.44 \mathrm{~mm} / \mathrm{yr}$. while the vertical velocity from GNSS is $+1.01 \mathrm{~mm} / \mathrm{yr}$. Especially areas of high uplift, or regional subsidence, suffer from very poor accuracy in estimating the vertical velocity [15]. The average relative rate of rise is $-0.38 \mathrm{~mm} / \mathrm{yr}$., the average acceleration 
is $+0.00120 \mathrm{~mm} / \mathrm{yr}$., and the average absolute rate of rise is $+0.73 \mathrm{~mm} / \mathrm{yr}$.

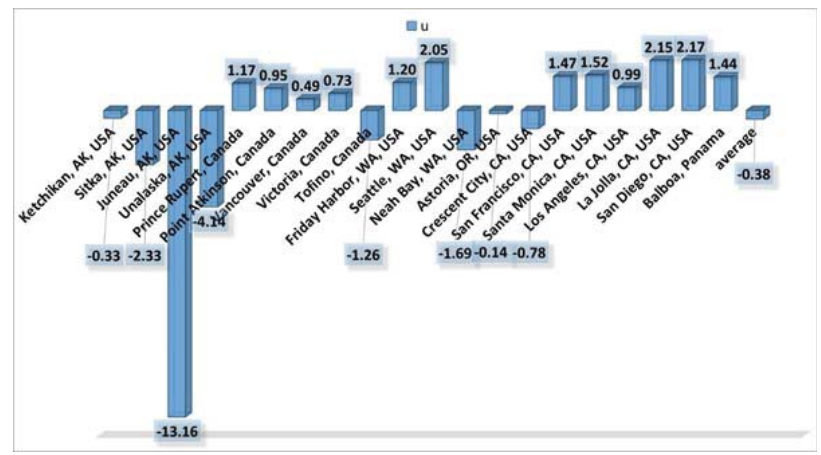

(a)

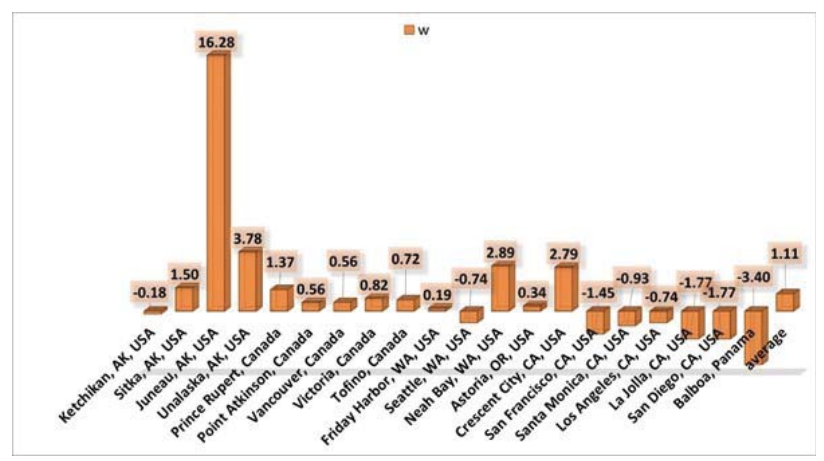

(b)

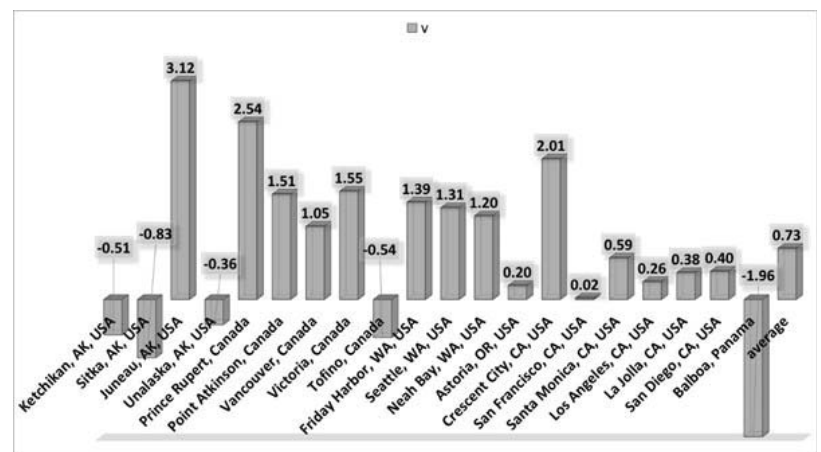

(c)

Figure 23: Summary of sea-level rise and subsidence results. $u$ is the relative sea-level rise, $w$ is the absolute vertical velocity at the GNSS antenna nearby the tide gauge, and $v=u+w$ is the absolute sea-level rise. Units are $\mathrm{mm} / \mathrm{yr}$.

The acceleration result is consistent with other global and regional estimations from LTT stations such as [17, 18] or $[19,20]$. [19] and [20] recently reported as the latest average acceleration of worldwide data sets is still very close to zero. The Mitrovica's 23 gold standard tide stations with minimal vertical land motion have average acceleration $+0.0020 \pm 0.0173 \mathrm{~mm} / \mathrm{yr}^{2}$. The Holgate’s nine ex- cellent tide gauge records of sea-level measurements have average acceleration $+0.0029 \pm 0.0118 \mathrm{~mm} / \mathrm{yr}^{2}$. The NOAA's 42 U.S. long term trend tide stations of 2011 have average acceleration $+0.0025 \pm 0.0308 \mathrm{~mm} / \mathrm{yr}^{2}$. The California8 long term trend tide stations have average acceleration $+0.0014 \pm 0.0266 \mathrm{~mm} / \mathrm{yr}^{2}$. The LTT stations of the West Coast of North America have acceleration values on average positive, but of the order of the nanometers per year squared, similarly to the other data sets.

\section{Conclusions}

The GNSS monitoring of the position of antennas is superior to the GIA model computations to assess vertical land velocities. The GIA is a global isostatic factor of theoretical model dimensions. The GNSS values are records of actual site-specific crustal movements. However, the technique still suffers from major uncertainties (differences between the estimates by different providers often larger than the trend). Although the GNSS measurements of vertical velocity still leave much to be desired, they are better than model estimates, based on GIA, of the rate of rise of the land. A particularly valuable part of the paper is the display of raw data on the relative changes of sea levels measured by tide gauges. A crisp summary of the results of linear and quadratic fits to the data is tabled. The measurements at the tide gauges are the best way to understand sea-level changes. These measurements show a stable pattern of mild rising sea levels with negligible accelerations mostly explained by the sinking of the tide gauge instrument, in the 20 LTT tide gauges of the West Coast of North America.

In Ketchikan, AK, USA, Sitka, AK, USA, Juneau, AK, USA, Unalaska, AK, USA, Prince Rupert, Canada, Point Atkinson, Canada, Vancouver, Canada, Victoria, Canada, Tofino, Canada, Friday Harbor, WA, USA, Seattle, WA, USA, Neah Bay, WA, USA, Astoria, OR, USA, Crescent City, CA, USA, San Francisco, CA, USA, Santa Monica, CA, USA, Los Angeles, CA, USA, La Jolla, CA, USA, San Diego, CA, USA and Balboa, Panama the average relative rate of rise is $-0.38 \mathrm{~mm} / \mathrm{yr}$., the average acceleration is $+0.0012 \mathrm{~mm} / \mathrm{yr}$., and the average absolute rate of rise is $+0.73 \mathrm{~mm} / \mathrm{yr}$.

As the GNSS values chosen are far are still uncertain and linked with very great scatter values, the absolute rate of rise result is less reliable than the relative rate of rise and acceleration results.

As the absolute rate of rise of the sea levels from thermal expansion of ocean waters and mass addition from melting of ice on land is small, in uplifting areas, sea level 
Table 1: Summary of sea-level rise and subsidence results. $u$ is the relative sea-level rise, $w$ is the absolute vertical velocity at the GNSS antenna nearby the tide gauge, and $v=u+w$ is the absolute sea-level rise.

\begin{tabular}{ccccccccc}
\hline tide gauge & start & end & range & $\begin{array}{c}u \\
m m / y r .\end{array}$ & $\begin{array}{c}a \\
m m / y r^{2}\end{array}$ & $\begin{array}{c}W \\
m m / y r .\end{array}$ & $\begin{array}{c}v \\
m m / y r .\end{array}$ & $\begin{array}{c}W^{*} \\
m m / y r\end{array}$ \\
\hline Ketchikan, AK, USA & 1919.04 & 2017.96 & 98.92 & -0.33 & -0.0181 & -0.18 & -0.51 & 0.10 \\
\hline Sitka, AK, USA & 1924.37 & 2017.96 & 93.59 & -2.33 & -0.0163 & 1.50 & -0.83 & -0.08 \\
\hline Juneau, AK, USA & 1936.04 & 2017.96 & 81.92 & -13.16 & -0.0378 & 16.28 & 3.12 & 1.34 \\
\hline Unalaska, AK, USA & 1934.04 & 2017.96 & 83.92 & -4.14 & -0.0145 & 3.78 & -0.36 & 0.40 \\
\hline Prince Rupert, Canada & 1909.04 & 2016.96 & 107.92 & 1.17 & 0.0148 & 1.37 & 2.54 & 0.43 \\
\hline Point Atkinson, Canada & 1914.37 & 2016.96 & 102.59 & 0.95 & -0.0053 & 0.56 & 1.51 & -0.11 \\
\hline Vancouver, Canada & 1909.87 & 2016.96 & 107.09 & 0.49 & 0.0251 & 0.56 & 1.05 & -0.14 \\
\hline Victoria, Canada & 1909.2 & 2016.96 & 107.76 & 0.73 & 0.0066 & 0.82 & 1.55 & -1.01 \\
\hline Tofino, Canada & 1909.79 & 2016.96 & 107.17 & -1.26 & 0.02 & 0.72 & -0.54 & -1.06 \\
\hline Friday Harbor, WA, USA & 1934.04 & 2017.96 & 83.92 & 1.20 & 0.0102 & 0.19 & 1.39 & -0.82 \\
\hline Seattle, WA, USA & 1899.04 & 2017.96 & 118.92 & 2.05 & 0.0099 & -0.74 & 1.31 & -1.30 \\
\hline Neah Bay, WA, USA & 1934.62 & 2017.96 & 83.34 & -1.69 & -0.0162 & 2.89 & 1.20 & -1.38 \\
\hline Astoria, OR, USA & 1925.12 & 2017.96 & 92.84 & -0.14 & 0.0148 & 0.34 & 0.20 & -1.79 \\
\hline Crescent City, CA, USA & 1933.04 & 2017.96 & 84.92 & -0.78 & -0.0086 & 2.79 & 2.01 & -0.93 \\
\hline San Francisco, CA, USA & 1854.54 & 2017.96 & 163.42 & 1.47 & 0.0141 & -1.45 & 0.02 & -0.71 \\
\hline Santa Monica, CA, USA & 1933.04 & 2017.96 & 84.92 & 1.52 & -0.0072 & -0.93 & 0.59 & -0.47 \\
\hline Los Angeles, CA, USA & 1923.96 & 2017.96 & 94 & 0.99 & 0.0177 & -0.74 & 0.26 & -0.48 \\
\hline La Jolla, CA, USA & 1924.87 & 2017.96 & 93.09 & 2.15 & 0.0112 & -1.77 & 0.38 & -0.46 \\
\hline San Diego, CA, USA & 1906.04 & 2017.96 & 111.92 & 2.17 & 0.0081 & -1.77 & 0.40 & -0.47 \\
\hline Balboa, Panama & 1908.04 & 2017.96 & 109.92 & 1.44 & -0.0055 & -3.40 & -1.96 & 0.13 \\
\hline & averages & & & -0.38 & 0.0012 & 1.11 & 0.73 & -0.44 \\
\hline
\end{tabular}

is decreasing, and the contrary happens in subsiding areas.

The influence of earthquakes, same as every other disturbance in the tide gauge signals, such as change of position of the tide gauge, or infrastructure extension changing the sea level pattern, should be taken into consideration.

\section{References}

[1] Schlesinger M., Ramankutty N., An oscillation in the global climate system of period 65-70 years, Nature, 1994, 367, 723726.

[2] Chambers D., Merrifield M.A., Nerem R.S., Is there a 60-year oscillation in global mean sea level?, Geophys. Res. Lett., 2012, 39(18), GL052885.

[3] www.psmsl.org, visited December 1, 2019.

[4] www.sealevel.info, visited December 1, 2019.

[5] tidesandcurrents.noaa.gov, visited December 1, 2019.

[6] www.sonel.org; visited December 1, 2019.

[7] Wöppelmann G., Marcos M., Vertical land motion as a key to understanding sea level change and variability, Rev. Geophys., 2016, 54(1), 64-92.

[8] geodesy.unr.edu, visited December 1, 2019.

[9] Blewitt G., Kreemer C., Hammond W.C., Gazeaux J., MIDAS robust trend estimator for accurate GNSS station velocities without step detection, J. Geophys. Res., 2016, 121, JB012552.

[10] sideshow.jpl.nasa.gov/post/series.html
[11] Parker A., Mörner N.A., Matlack-Klein P., Sea level acceleration caused by earthquake induced subsidence in the Samoa Islands, Ocean Coast. Managem., 2018, 161, 11-19.

[12] Mörner N.A., Klein P.M., The Fiji tide-gauge stations, Int. J. Geosci., 2017, 8(04), 536.

[13] Peltier W.R., Postglacial Variations in the Level of the Sea: Implications for Climate Dynamics and Solid-Earth Geophysics, Rev. Geophys., 1998, 36(4), 603-689.

[14] Peltier W.R., Global Glacial Isostasy and the Surface of the IceAge Earth: The ICE-5G(VM2) model and GRACE, Ann. Rev. Earth. Planet. Sci., 2004, 32, 111-149.

[15] Mörner N.A., Glacial Isostasy: Regional-Not Global, Int. J. Geosci., 2015, 6(06), 577.

[16] Wöppelmann G., Letetrel C., Santamaria A., Bouin M.-N., Collilieux X., Altamimi Z. et al., Rates of sea-level change over the past century in a geocentric reference frame, Geophys. Res. Lett., 2009, 36, L12607.

[17] Houston J.R., Dean R.G., Sea-Level Acceleration Based on U.S. Tide Gauges and Extensions of Previous Global-Gauge Analyses, J. Coast. Res., 2011, 27, 409-417.

[18] Parker A., Sea level trends at locations of the United States with more than 100 years of recording, Nat. Hazards, 2013, 65(1), 1011-1021.

[19] Parker A., Ollier C.D., California sea level rise: evidence based forecasts vs. model predictions, Ocean Coast. Manag., 2017, 149, 198-209.

[20] Parker A., Ollier C.D., Short-Term Tide Gauge Records from One Location are Inadequate to Infer Global Sea-Level Acceleration, Earth Systems Environ., 2017, 1(2), 17.

[21] Parker A., Saad Saleem M., Lawson M., Sea-Level Trend Analysis for Coastal Management, Ocean and Coastal Manag., 2013, 
73, 63-81.

[22] Douglas B., Global Sea Level Acceleration, J. Geophys. Res., 1992, 97(8), 12,699-12,706.

[23] Douglas B., Peltier W.R., The Puzzle of Global Sea-Level Rise, Phys. Today, 2002, 55(3), 35-40.

[24] Jevrejeva S., Grinsted A., Moore J.C., Holgate S., Nonlinear trends and multiyear cycles in sea level records, J. Geophys. Res.: Oceans, 2006, 111(C9), JC003229.

[25] Holgate S.J., On the decadal rates of sea level change during the twentieth century, Geophys. Res. Lett., 2007, 34, L01602.

[26] Wunsch R., Ponte R., Heimbach P., Decadal trends in sea level patterns: 1993-2004, J. Climatol., 2007, 20(24), 5889-5911.

[27] Wenzel M., Schröter J., Reconstruction of regional mean sea level anomalies from tide gauges using neural networks, J. Geophys. Res.: Oceans, 2010, 115, C08013.

[28] Parker A., Oscillations of sea level rise along the Atlantic coast of North America north of Cape Hatteras, Nat. Hazards, 2013, 65(1), 991-997.

[29] Mörner N.-A., Rates of Sea Level Changes - A Clarifying Note, by Nils-Axel Mörner, Int. J. Geosci., 2016, 7(11), 1318-1322.

[30] Mörner N.-A., Sea level changes in Bangladesh new observational facts, Energy Environ., 2010, 21(3), 235-249.

[31] Mörner N.-A., Some problems in the reconstruction of mean sea level and its changes with time, Quarter. Int., 2010, 221(12), 3-8.

[32] Mörner N.-A., There Is No Alarming Sea Level Rise! 21st Century Science and Technology, 2010, Fall, 7-17.

[33] Mörner N.-A., Setting the frames of expected future sea level changes by exploring past geological sea level records, Chapter 6 of book, Easterbrook D., Evidence-Based Climate Science, 2011, Elsevier, ISBN: 978-0-12-385956-3.

[34] Mörner N.-A., The Maldives: A measure of sea level changes and sea level ethics, Chapter 7 of book, Easterbrook D., Evidence-Based Climate Science, 2011, Elsevier, ISBN: 9780-12-385956-3.
[35] Beenstock M., Reingewertz Y., Paldor N., Polynomial cointegration tests of anthropogenic impact on global warming, Earth Syst. Dyn., 2012, 3(2), 173-188.

[36] Beenstock M., Felsenstein D., Frank E., Reingewertz Y., Tide gauge location and the measurement of global sea level rise, Environ. Ecolog. Stat., 2015, 22(1), 179-206.

[37] Boretti A., Short Term Comparison of Climate Model Predictions and Satellite Altimeter Measurements of Sea Levels, Coastal Eng., 2012, 60, 319-322.

[38] Boretti A., Is there any support in the long term tide gauge data to the claims that parts of Sydney will be swamped by rising sea levels?, Coastal Eng., 2012, 64, 161-167.

[39] Boretti A., Watson T., The inconvenient truth: Ocean Levels are not accelerating in Australia, Energy Environ., 2012, 23(5), 801-817.

[40] Dean R.G., Houston J.R., Recent sea level trends and accelerations: comparison of tide gauge and satellite results, Coastal Eng., 2013, 75, 4-9.

[41] Scafetta N., Multi-scale dynamical analysis (MSDA) of sea level records versus PDO, AMO, and NAO indexes, Climate Dyn., 2014, 43, 175-192.

[42] Schmith T., Johansen S., Thejll P., Statistical analysis of global surface temperature and sea level using cointegration methods, J. Climate, 2012, 25(22), 7822-7833.

[43] Parker A., Apparent hot and cold spots of acceleration along the Atlantic and Pacific coasts of the United States, Nonlin. Eng., 2013, 3(1), 51-56.

[44] Parker A., Ollier C.D., Sea level rise for India since the start of tide gauge records, Arab. J. Geosci., 2015, 8(9), 6483-6495.

[45] Parker A., Impacts of sea level rise on coastal planning in Norway, Ocean Eng., 2014, 78(1), 124-130.

[46] Zervas R., Sea Level Variations of the United States 18542006, NOAA Technical Report NOS CO-OPS 053, 2009, 15-24. 